\title{
Use of Autologous Stem Cells for the Regeneration of Periodontal Defects in Animal Studies: a Systematic Review and Meta- Analysis
}

\author{
Algimantas Gaubys ${ }^{1}$, Valdas Papeckys ${ }^{1}$, Mindaugas Pranskunas ${ }^{1}$ \\ ${ }^{1}$ Department of Maxillofacial Surgery, Lithuanian University of Health Sciences, Kaunas, Lithuania.
}

\author{
Corresponding Author: \\ Algimantas Gaubys \\ Ukmerges g. 9A, LT-49342, Kaunas \\ Lithuania \\ Phone: +37063463824 \\ E-mail: gaubys.algimantas@gmail.com
}

\begin{abstract}
Objectives: To overview preclinical animal trials and quantify the effect size that stem cell therapy has on the regeneration of periodontal tissue complex.

Material and Methods: A systematic MEDLINE (PubMed) online library search was conducted for preclinical animal studies in vivo, using autologous periodontal ligament, dental pulp, cementum, alveolar periosteal, gingival margin or adipose stem cell types for periodontal tissue complex regeneration purposes. Studies had to be published between 2007.09.01 and 2017.09.01 in the English language.

Results: Online library search yielded 2099 results. After the title, abstract and full-text screening ten studies fit inclusion criteria and were pooled into meta-analysis. Overall the stem cell regenerative therapy had a statistically significant positive influence on the periodontal tissue regeneration when compared to the control groups. The biggest influence was made to the regeneration of cementum (standardised mean difference [SMD] 2.25 [95\% confidence interval $(\mathrm{CI})=1.31$ to 3.2$]$ ) while the smallest influence was made to the alveolar bone (SMD 1.47 [95\% CI $=0.7$ to 2.25]) the effect size for periodontal ligament regeneration was (SMD $1.8[95 \% \mathrm{CI}=1$ to 2.59$]$ ). Subgroup analysis showed statistically significant $(\mathrm{P}<0.05)$ differences between different cell types in the alveolar bone and cementum regeneration groups and in alveolar bone group in relation to scaffold materials.

Conclusions: Stem cell therapy has a positive impact on periodontal tissue complex regeneration. Such therapy has the biggest influence on cementum regeneration meanwhile alveolar bone regeneration is influenced by the least amount. However more and less diverse preclinical studies are needed to have a greater statistical power in future meta-analyses.
\end{abstract}

Keywords: mesenchymal stromal cells; periodontal diseases; stem cells; tissue engineering.

Accepted for publication: 24 May 2018

To cite this article:

Gaubys A, Papeckys V, Pranskunas M.

Use of Autologous Stem Cells for the Regeneration of Periodontal Defects in Animal Studies: a Systematic Review and MetaAnalysis

J Oral Maxillofac Res 2018;9(2):e3

URL: http://www.ejomr.org/JOMR/archives/2018/2/e3/v9n2e3.pdf

doi: $10.5037 /$ jomr.2018.9203 


\section{INTRODUCTION}

The periodontium is a complex organ comprising of four mesenchymal tissue components (cementum, alveolar bone, gingiva and periodontal ligament) that act as a functional unit, providing the tooth with a masticatory load dampening system and an attachment to the surrounding alveolus. Periodontal tissues are capable of withstanding substantial masticatory forces. However, they are susceptible to damage from mechanical, chemical trauma or bacterial infection. Periodontal disease is one of the most prevalent diseases in the field of dentistry, found in 20 to $50 \%$ of the global adult population [1, 2$]$. It is the leading cause of tooth loss due to the degeneration of periodontium [2], which leads to substantial reduction in oral health and overall quality of life [2-4]. The goals of periodontal therapy include the arrest of periodontal disease progression and the regeneration of damaged periodontal tissues by promoting the formation of alveolar bone, cementum, and periodontal ligament structures. Various periodontal tissue regenerative therapies such as guided tissue regeneration, bone grafting and placement of various biomaterials, such as enamel matrix proteins, platelet-rich plasma (PRP) have been routinely utilized in clinical practice for decades $[\underline{5}, 6]$. These therapies result in an overall improvement to periodontal tissue health. However clinical results have limited predictability due to being sensitive to patient behaviour, surgical approach and periodontal defect morphology, favouring narrow, confined intrabony defects $[\underline{7}, \underline{8}]$.

In recent years scientific advances in cytotherapeutics led to the increasing emphasis on developing a cellbased periodontal tissue treatment [9-11]. Periodontal tissue contains many types of cells including mature multipotent mesenchymal stem cells (MSCs) $[\underline{10}, \underline{11}]$. They are self-renewable, highly proliferative progenitor cells with a potential to differentiate into adult mesenchymal cell types, including fibroblastic, osteoblastic, and cementoblastic lineages [10-13]. Because of these unique properties, MSCs delivered in situ to tissue defects can stimulate neovascularization and lead to faster tissue regeneration $[10,14]$. Furthermore due to immuno-modulatory functions, observed in MSCs, they may halt the development of tissue injury and allow regenerative processes to take place [10]. Various stem cell types, including but not limited to periodontal ligament, adipose tissue, alveolar periosteal and dental pulp stem cells have been used as a treatment option for periodontal tissue regeneration $[\underline{10}, \underline{15}]$. A number of literature reviews overviewing periodontal tissue regeneration by stem cell therapy have been published previously [16-20]. However, only one meta-analysis was published on this topic, which did not involve periodontal ligament regeneration analyses and put emphasis only on the regeneration of alveolar bone, and cementum tissues [16]. Therefore, this study aims to compare various types of mesenchymal stem cells, different periodontal defect treatment durations and various scaffolding or cell carrier materials in relation to the regeneration of periodontal tissue defects. Particular emphasis is put on quantitative data on the regeneration of alveolar bone, periodontal ligament, and cementum.

\section{MATERIAL AND METHODS Protocol}

This systematic review was conducted following the Preferred Reporting Items for Systematic Reviews and Meta-Analyses (PRISMA) statement for systematic reviews [21].

\section{Focus questions}

The following focus questions were developed according to the population, intervention, comparison, and outcome (PICO) study design:

Does stem cell therapy make a statistically significant improvement in the quantitative results of periodontal tissue (periodontal ligament, alveolar bone, cementum) regeneration?

Which type of stem cell, scaffold material, and treatment duration has the biggest influence to periodontal tissue regeneration?

\section{Types of publications}

The review included studies on animals in vivo published in the English language.

\section{Types of studies}

This review included preclinical in vivo animal trials. Systematic literature reviews, meta-analyses, pilot studies and case reviews were excluded.

\section{Information sources}

Systematic article search was performed in MEDLINE (PubMed) online library.

\section{Literature search strategy}

The online search strategy was: "Periodont*" AND 
"Regenerat*" AND ("Stem" OR "Adipose" OR "Periodontal" OR "Pulp") AND "Cell". Search was limited to studies published in the English language from September 2007 to September 2017. Flow diagram of search results according to PRISMA guidelines is presented in Figure 1.

\section{Selection of studies}

A primary literature search was performed by screening article titles. Abstracts were read when relevant titles were found. Full texts were screened when abstracts were relevant or unavailable. Full texts fitting our inclusion criteria were included in the meta-analysis. Systematic literature search and data collection were repeated by two independent researchers (A.G. and V.P.). Disagreements about study inclusion were resolved by a method of discussion with a third independent researcher (M.P.).

\section{Inclusion and exclusion criteria}

Inclusion criteria for the selection were: preclinical animal trials conducted in vivo, whose primary aim had to be periodontal defect regeneration using therapy utilizing autologous stem cells from the following origin sites: periodontal ligament, dental pulp, cementum, alveolar periosteum, gingival margin or adipose tissue. Periodontal defects had to be caused by a controlled mechanical intervention (surgery). Studies had to report quantitative data on regeneration in both treatment and control groups on at least one of the following periodontal tissues: periodontal ligament, alveolar bone, cementum.

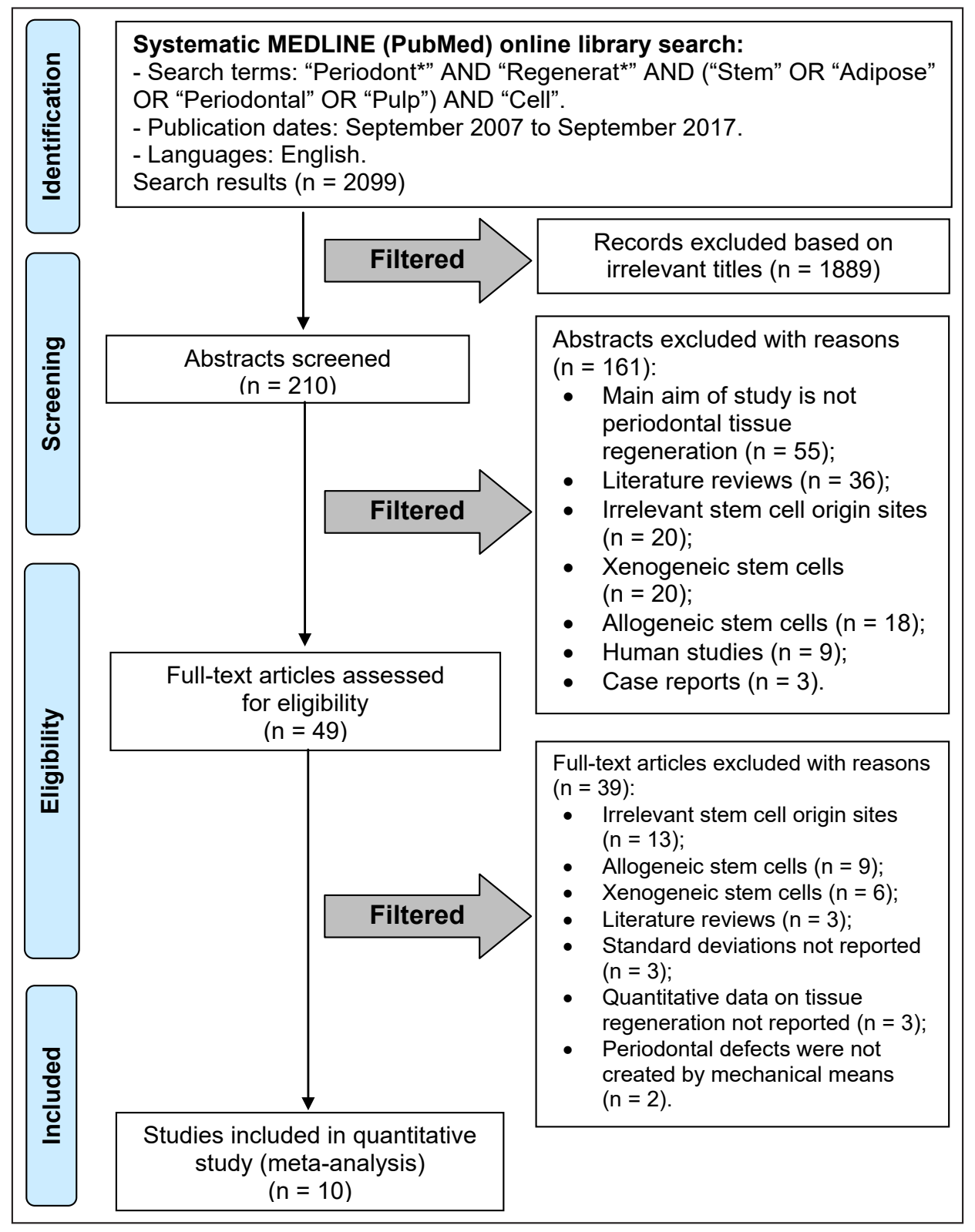

Figure 1. Flow diagram of studies selection according PRISMA guidelines. 
Exclusion criteria for the selection were: systematic literature reviews, meta-analyses, pilot studies and case reviews or preclinical studies conducted on humans or animals ex vivo or in vitro whose main aim was not the regeneration of periodontal defects. Studies in which periodontal defects were caused by degeneration of tissues due to local or systemic infection. Studies in which quantitative data on periodontal tissue regeneration was not reported or did not include one or more of the following pieces of statistical information: mean treatment effect size in treatment or control groups, effect size standard deviation, and the total number of cases in treatment and control groups.

\section{Sequential search strategy}

All article titles were independently screened by two researchers (A.G. and V.P.) to eliminate irrelevant publications considering the exclusion criteria. Next, irrelevant studies were excluded based on data obtained after reading the abstracts. Disagreements about study inclusion were resolved by a method of discussion with a third independent researcher (M.P.). At the final stage, the full texts were screened based on the inclusion criteria to confirm the eligibility of each study.

\section{Data extraction}

The data were independently extracted from the studies according to the aims and themes of the present review. Data collection form was employed to ensure systematic recording of data.

\section{Data items}

Data were collected from the included articles and arranged in the following fields (Table 1):

- "Study or subgroup" - reveals the author and year of publication.

- "Animal type" - describes the type and number (n) of animals who were treated with stem cell therapy. The age of animals was recorded when reported.

- "Cell source" - describes the tissue MSCs have been isolated from.

- "Defect type (dimensions)" - describes the type of created periodontal tissue defects, their dimensions (height in occlusoapical direction, the width in mesiodistal direction and length in buccolingual direction) and number (n) of defects in each treatment group.

- "Treatment duration" - reveals the duration of treatment in weeks.
"Scaffold" - describes the type of scaffold material used in the study.

- "Treatment groups" - describes the individual treatment groups. Irrelevant treatment groups (such as groups using stem cell types irrelevant to the present study) were not reported and were not used in the meta-analysis of this study.

- "Number of defects treated" - describes the number of defects treated in each treatment group.

- "Periodontal ligament regeneration" - describes the quantitative data (mean and standard deviation) on periodontal tissue regeneration in treatment and control groups. Regenerated tissue height was either measured in millimetres from defect baseline or was compared with the total defect height and expressed as a percentage value, as reported by study authors.

- "Alveolar bone regeneration" - describes the quantitative data (mean and standard deviation) on periodontal tissue regeneration in treatment and control groups. Regenerated tissue height was either measured in millimetres from defect baseline or was compared with the total defect height and expressed as a percentage value, as reported by study authors.

- "Cementum regeneration" - describes the quantitative data (mean and standard deviation) on periodontal tissue regeneration in treatment and control groups. Regenerated tissue height was either measured in millimetres from defect baseline or was compared with the total defect height and expressed as a percentage value, as reported by study authors.

Studies, which had more than one experimental treatment group were included as separate substudies in the meta-analysis, such sub-studies were denoted with ' $a$ ' or ' $b$ ' subscript letters in forest plots. Treatment groups which did not involve any therapy after the surgical creation of periodontal tissue defects were classified as control groups.

\section{Risk of bias assessment}

Individual study bias was assessed according to the Cochrane's risk of bias tool [22]. Following criteria were used to determine the bias level of each study: random sequence generation, allocation concealment, blinding of personnel, blinding of outcome assessment, incomplete outcome data, selective reporting and other sources of bias (Table 2). The studies were categorized as low risk of bias if all following criteria were met, moderate risk of bias if one of the latter criteria were not included, high risk of bias if two or more criteria were missing. 
Table 1. Studies included in the meta-analysis

\begin{tabular}{|c|c|c|c|c|c|c|c|c|c|c|c|c|}
\hline \multirow[b]{2}{*}{ Study } & & \multirow[b]{2}{*}{$\begin{array}{c}\text { Year of } \\
\text { publication }\end{array}$} & \multicolumn{7}{|c|}{ Materials and methods } & \multicolumn{3}{|c|}{ Outcome measures } \\
\hline & & & $\underset{\text { (n) }}{\text { Animal type }}$ & Cell source & $\begin{array}{l}\text { Defect type } \\
\text { (dimensions) }\end{array}$ & $\begin{array}{l}\text { Treatment } \\
\text { duration } \\
\text { in weeks }\end{array}$ & Scaffold & Treatment groups & $\begin{array}{l}\text { Number of } \\
\text { defects treated }\end{array}$ & $\begin{array}{l}\text { Periodontal ligament } \\
\quad \text { regeneration, } \\
\text { mean (SD) }\end{array}$ & $\begin{array}{l}\text { Alveolar bone } \\
\text { regeneration, } \\
\text { mean (SD) }\end{array}$ & $\begin{array}{c}\text { Cementum } \\
\text { regeneration, } \\
\text { mean (SD) }\end{array}$ \\
\hline \multirow{2}{*}{\multicolumn{2}{|c|}{ Jiang et al. [62] }} & \multirow{2}{*}{2016} & \multirow{2}{*}{$\begin{array}{l}\text { Male Beagle dogs. } \\
6-8 \text { months of age } \\
(\mathrm{n}=6)\end{array}$} & \multirow{2}{*}{ Periodontal ligament } & \multirow{2}{*}{$\begin{array}{c}\text { 3-wall intrabony } \\
\text { periodontal defect } \\
(\mathrm{H} \times \mathrm{W} \times \mathrm{L}=5 \times 4 \times 3 \mathrm{~mm})\end{array}$} & \multirow[b]{2}{*}{12} & \multirow{2}{*}{ Collagen sponge } & PDLCs + collagen membrane & 9 & \multirow{2}{*}{ No data } & $29.1(6.6) \%$ & $29.2(16.4) \%$ \\
\hline & & & & & & & & Control & 9 & & $15.2(4.9) \%$ & $19.4(4.3) \%$ \\
\hline \multirow{3}{*}{ Nuñez et al. [63] } & $\mathrm{a}$ & \multirow{3}{*}{2012} & \multirow{3}{*}{$\begin{array}{l}\text { Adult Beagle dogs. } \\
1 \text { year old } \\
(\mathrm{n}=4)\end{array}$} & \multirow{3}{*}{$\begin{array}{l}\text { Periodontal ligament } \\
\text { and cementum }\end{array}$} & \multirow{3}{*}{$\begin{array}{c}\text { 3-wall intrabony } \\
\text { periodontal defect } \\
(\mathrm{H} \times \mathrm{W} \times \mathrm{L}=4 \times 4 \times 4 \mathrm{~mm})\end{array}$} & \multirow{3}{*}{12} & \multirow{3}{*}{ Collagen sponge } & CSCs + collagen sponge & 8 & \multirow{3}{*}{ No data } & $2.6(0.4) \mathrm{mm}$ & $4(0.6) \mathrm{mm}$ \\
\hline & $\mathrm{b}$ & & & & & & & PLDCs + collagen sponge & 8 & & $3.1(1.1) \mathrm{mm}$ & $4.1(1) \mathrm{mm}$ \\
\hline & $\mathrm{a}, \mathrm{b}$ & & & & & & & Control & 8 & & $2.6(0.7) \mathrm{mm}$ & $1.6(0.4) \mathrm{mm}$ \\
\hline \multirow{2}{*}{\multicolumn{2}{|c|}{ Liu et al. [64] }} & \multirow{2}{*}{2008} & \multirow{2}{*}{$\begin{array}{l}\text { Miniature pigs. } \\
12 \text { months old } \\
(\mathrm{n}=12)\end{array}$} & \multirow{2}{*}{ Periodontal ligament } & \multirow{2}{*}{$\begin{array}{c}\text { 3-wall intrabony } \\
\text { periodontal defect } \\
(\mathrm{H} \times \mathrm{W} \times \mathrm{L}=7 \times 3 \times 5 \mathrm{~mm})\end{array}$} & \multirow{2}{*}{12} & \multirow{2}{*}{$\mathrm{HA} / \mathrm{TCP}$} & PDLSC + HA/TCP & 24 & \multirow{2}{*}{ No data } & $3.5(0.7) \mathrm{mm}$ & \multirow{2}{*}{ No data } \\
\hline & & & & & & & & Control & 12 & & $0.5(0.4) \mathrm{mm}$ & \\
\hline \multirow{2}{*}{\multicolumn{2}{|c|}{ Jiang et al. [65] }} & 2010 & Adult Beagle dogs & Alveolar neriosteum & Class III furcation defect & 12 & В-ТCP & $\mathrm{APSCs}+\beta-\mathrm{TCP}$ & 4 & $33.6(13.8) \%$ & $60.2(18.2) \%$ & $50.8(8.2) \%$ \\
\hline & & 2010 & $(\mathrm{n}=4)$ & Alveotal perioste tili & $(\mathrm{H} \times \mathrm{W}=4 \times 3 \mathrm{~mm})$ & 12 & $\beta-1 C P$ & Control & 4 & $17.7(5.4) \%$ & $22.6(7.3) \%$ & $31.7(12.9) \%$ \\
\hline & $\mathrm{a}$ & & & & Circumferential & & & PDLSCs & 8 & & $82.8(7.9) \%$ & \\
\hline Park et al. [66] & $\mathrm{b}$ & 2011 & $\begin{array}{l}\text { Adult Beagle dogs } \\
(\mathrm{n}=8)\end{array}$ & Periodontal ligament & periodontal defect & 8 & No scaffold & DPSCs & 8 & No data & $50.8(9.6) \%$ & No data \\
\hline & $\mathrm{a}, \mathrm{b}$ & & & & & & & Control & 8 & & $47.9(13.4) \%$ & \\
\hline Suaid et al [67] & & 2011 & Adult Beagle dogs & Periodontal ligament & Class II furcation defect & 12 & Collagen sponoe & PDLCs + collagen sponge & 7 & $7.3(1) \mathrm{mm}$ & $9(2.3) \mathrm{mm}^{2}$ & $8.1(1.1) \mathrm{mm}$ \\
\hline 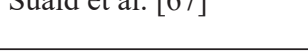 & & 2011 & $(\mathrm{n}=7)$ & 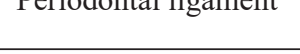 & $(\mathrm{H} \times \mathrm{L}=5 \times 2 \mathrm{~mm})$ & 12 & - vilager sponige & Control & 7 & $3.9(1.2) \mathrm{mm}$ & $7(0.6) \mathrm{mm}^{2}$ & $6(1.5) \mathrm{mm}$ \\
\hline & $\mathrm{a}$ & & & & One-wall intrabony & & & PDLCs + PGA & 4 & & $72.3(32.6) \%$ & \\
\hline Tsumanuma et al. [68] & $\mathrm{b}$ & 2011 & $\begin{array}{l}\text { Adult Beagle dogs } \\
(\mathrm{n}=4)\end{array}$ & $\begin{array}{l}\text { ererodontal ligament; } \\
\text { alveolar periosteum }\end{array}$ & periodontal defect & 8 & $\begin{array}{l}\text { Woven } \\
\text { polvglycolic acid }\end{array}$ & APSCs + PGA & 4 & No data & $67.6(21.6) \%$ & No data \\
\hline & $\mathrm{a}, \mathrm{b}$ & & & & $(\mathrm{H} \times \mathrm{W}=5 \times 5 \mathrm{~mm})$ & & & Control & 4 & & $67.5(14.3) \%$ & \\
\hline Suaid et al. [69] & & 2012 & Adult Beagle dogs & Periodontal ligament & Class III furcation defect & 12 & Collaren snonoe & PDLCs + Sponge + GTR & 7 & $3.4(1.4) \mathrm{mm}$ & $5.5(1.6) \mathrm{mm}$ & $4.8(0.6) \mathrm{mm}$ \\
\hline Suald et al. [09] & & 2012 & $(\mathrm{n}=7)$ & Periodontal Iigament & $(\mathrm{H}=5 \mathrm{~mm})$ & 12 & Collagen sponge & Control & 7 & $0.7(0.6) \mathrm{mm}$ & $1.9(1) \mathrm{mm}$ & $1.7(0.6) \mathrm{mm}$ \\
\hline & & & Male, Mongrel dogs. & & 3-wall intrabony & & & DPSCs + Bio-Oss & 10 & $3.3(1.1) \mathrm{mm}$ & $3.6(1.1) \mathrm{mm}$ & $3.8(1.3) \mathrm{mm}$ \\
\hline Khorsand et al. [70] & & 2013 & $\begin{array}{c}1-2 \text { years of age } \\
(\mathrm{n}=10)\end{array}$ & Dental pulp & $\begin{array}{c}\text { periodontal defect } \\
(\mathrm{H} \times \mathrm{W} \times \mathrm{L}=5 \times 8 \times 3 \mathrm{~mm})\end{array}$ & 8 & Bio-Oss & Control & 10 & $1.8(1.3) \mathrm{mm}$ & $3.1(0.8) \mathrm{mm}$ & $2.4(1.4) \mathrm{mm}$ \\
\hline & & & & & & & & $\mathrm{ASC}+\mathrm{PRP}$ & 8 & & $63.6(8.6) \%$ & $84.7(3.2) \%$ \\
\hline Tobita et al. [71] & & 2013 & $\begin{array}{c}9-10 \text { months old } \\
(\mathrm{n}=8)\end{array}$ & Adipose tissue & $(\mathrm{H}=5 \mathrm{~mm})$ & 8 & PRP & Control & 8 & No data & $40.3(7.6) \%$ & $61.7(10.5) \%$ \\
\hline
\end{tabular}

$\mathrm{n}=$ number of animals; $\mathrm{SD}=$ standard deviation; PDLCs = periodontal ligament stem cells; $\mathrm{DPSCs}=$ dental pulp stem cells; $\mathrm{ASC}=$ adipose tissue stem cells; $\mathrm{PRP}=$ platelet-rich plasma; $\mathrm{GTR}=$ guided tissue regeneration; $\mathrm{CSCs}=$ cementum stem cells; PGA = woven

polyglycolic acid; $\mathrm{APSCs}=$ alveolar periosteal stem cells; $\beta$-TCP $=\beta$-tricalcium phosphate; $\mathrm{HA} / \mathrm{TCP}=$ hydroxyapatite/tricalcium phosphate.
'a' and 'b' letters denotes different treatment groups within the same study.

Table 2. Assessment of risk of bias in individual studies

\begin{tabular}{l|c|c|c|c|c|c|c|c}
\hline \multicolumn{1}{c|}{ Study } & $\begin{array}{c}\text { Random } \\
\text { sequence } \\
\text { generation }\end{array}$ & $\begin{array}{c}\text { Allocation } \\
\text { concealment }\end{array}$ & $\begin{array}{c}\text { Blinding of } \\
\text { personnel }\end{array}$ & $\begin{array}{c}\text { Blinding of } \\
\text { outeme } \\
\text { assessment }\end{array}$ & $\begin{array}{c}\text { Incomplete } \\
\text { outcome data }\end{array}$ & $\begin{array}{c}\text { Selective } \\
\text { reporting }\end{array}$ & $\begin{array}{c}\text { Other } \\
\text { sources of } \\
\text { bias }\end{array}$ & $\begin{array}{c}\text { Overall } \\
\text { bias }\end{array}$ \\
\hline Jiang et al. [62] & + & $?$ & $?$ & + & + & + & - & $?$ \\
\hline Nuñez et al. [63] & + & $?$ & $?$ & + & + & + & - & $?$ \\
\hline Liu et al. [64] & + & - & - & $?$ & - & + & - & - \\
\hline Jiang et al. [65] & + & $?$ & $?$ & $?$ & + & + & - & - \\
\hline Park et al. [66] & + & $?$ & $?$ & $?$ & - & + & - & - \\
\hline Suaid et al. [67] & + & $?$ & $?$ & $?$ & + & + & - & - \\
\hline Tsumanuma et al. [68] & $?$ & $?$ & $?$ & + & + & + & - & - \\
\hline Suaid et al. [69] & + & - & + & $?$ & - & + & - & - \\
\hline Khorsand et al. [70] & + & $?$ & $?$ & $?$ & - & + & - & - \\
\hline Tobita et al. [71] & $?$ & $?$ & $?$ & $?$ & - & + & - & - \\
\hline
\end{tabular}

$+=$ low risk of bias; ? = unclear risk of bias; $-=$ high risk of bias. 


\section{Statistical analysis}

Statistical analysis was performed using Review Manager (RevMan Version 5.3. Copenhagen: The Nordic Cochrane Centre, The Cochrane Collaboration, 2014). Separate meta-analyses were performed on periodontal ligament, alveolar bone, and cementum regeneration measures by using $\mathrm{Z}$ test with random effects weighted inverse variance method. Due to the differing quantitative periodontal tissue regeneration measures standardised mean difference meta-analysis was chosen. Study heterogeneity was assessed using Cochran's Q and $\mathrm{I}^{2}$ tests. Due to a high level of heterogeneity across pooled studies subgroup analyses were performed using Chi-square test according to the scaffold type, treatment duration and stem cell types. The results were considered significant when $\mathrm{P}<0.05$.

\section{RESULTS \\ Study selection}

Online library search yielded 2099 results. After title screening for relevancy, 210 abstracts were found relevant. After abstract screening, 161 abstracts were excluded and 49 full-text articles were reviewed according to our study selection criteria. Thirty-nine full-text articles [23-61] were excluded with reasons. Ten articles [62-71] fit our inclusion criteria and were pooled into the meta-analysis (Figure 1).

\section{Exclusion of studies}

The reasons for excluding studies after a full-text assessment were as follows: irrelevant stem cell origin sites $(n=13)$ [23-35], allogeneic stem cells ( =9) [36-44], xenogeneic stem cells $(n=6)$ [45-50], literature reviews $(n=3)$ [51-53], standard deviations not reported $(\mathrm{n}=3)$ [54-56], quantitative data on tissue regeneration not reported $(\mathrm{n}=3)$ [57-59], periodontal defects were not created by mechanical means $(\mathrm{n}=2)$ [60-61].

\section{Risk of bias in individual studies}

Jiang et al. [62] and Nuñez et al. [63] conducted studies categorized as having medium risk of bias. All of the other studies were deemed as having a high risk of bias [64-71]. Most of the studies conducted randomization of test and control groups [62$\underline{67}, \underline{69}, \underline{70}]$. None of the reviewed articles submitted selective reporting. All of the included studies presented other forms of bias, such as not calculating sample size (Table 2).

\section{Study characteristics}

Periodontal defect types varied across studies with the majority being three-wall intrabony defects (4 studies) $[\underline{62-64}, \underline{70}]$, three studies created Class III furcation defects $[\underline{65}, \underline{69}, \underline{71}]$. Class II furcation defects [67], circumferential periodontal tissue defects [66] and one-wall intrabony periodontal defects [68] were created in 1 study each. Periodontal defect dimensions varied across studies. Only four articles $[65,67,69,70]$ reported all of the three dimensions of created defects: height in occlusoapical direction, width in mesiodistal direction and length in buccolingual direction. Nine out of 10 studies were performed on dogs $[62,63, \underline{65-}$ 71], the majority of them were adult Beagle dogs (8 studies), 1 study was conducted on adult Mongrel dogs [70]. Miniature pigs were treated in one study [64]. Treatment duration varied from 8 to 12 weeks across different studies. The most frequently adopted treatment duration was 12 weeks (6 out of 10 studies) [ $62-65, \underline{67}, \underline{69}]$. Different scaffolding materials were also used in our study pool with the most common scaffolding material being collagen sponges $[\underline{62}, \underline{63}, \underline{67}, \underline{69}]$. The included studies and study characteristics are shown in Table 1.

\section{Efficacy of stem cell therapy for periodontal tissue regeneration \\ Periodontal ligament regeneration}

Four studies $[\underline{65}, \underline{67}, \underline{69}, \underline{70}]$ reported data on periodontal ligament regeneration after the regenerative therapy. Study results were slightly heterogeneous $\left(\mathrm{I}^{2}=25 \%\right.$; Chi-square $\left.=4 ; \mathrm{P}=0.26\right)$. All of the studies reported stem cell therapy having a positive impact on periodontal ligament treatment results. Overall stem cell regenerative therapy significantly enhanced the regeneration of periodontal ligament (standardised mean difference [SMD] of 1.8 [95\% confidence interval $(\mathrm{CI})=1$ to 2.59 ]; $\mathrm{P}<0.00001$ ) (Figure 2).

Subgroup analyses indicated that the biggest positive impact on periodontal ligament regeneration occurred in groups, where stem cells were of periodontal ligament origin, treatment duration was 12 weeks and collagen sponges were used as a scaffold (Figures 3 - 5). However, none of these results are statistically significant and all of the subgroups had only 1 to 2 studies thus indicating a low statistical power.

\section{Alveolar bone regeneration}

All of the ten studies reported data on the alveolar bone regeneration. Study results were of high 


\begin{tabular}{|c|c|c|c|c|c|c|c|c|c|c|c|}
\hline \multirow[b]{2}{*}{ Study or Subgroup } & \multicolumn{3}{|c|}{ Stem cell group } & \multicolumn{3}{|c|}{ Control group } & \multicolumn{2}{|r|}{ Std. Mean Difference } & \multirow{2}{*}{\multicolumn{2}{|c|}{$\begin{array}{l}\text { Std. Mean Difference } \\
\text { IV, Random, } 95 \% \mathrm{Cl}\end{array}$}} & \\
\hline & Mean & SD & Total & Mean & SD & Total & Weight & IV, Random, $95 \% \mathrm{Cl}$ & & & \\
\hline Jiang et al., (2010) [65] & 33.6 & 13.8 & 4 & 17.7 & 5.4 & 4 & $18.6 \%$ & $1.32[-0.34,2.98]$ & & & \\
\hline Suaid et al., (2011) [67] & 7.3 & 1 & 7 & 3.9 & 1.2 & 7 & $18.9 \%$ & $2.88[1.24,4.52]$ & & & \\
\hline Suaid et al., (2012) [69] & 3.4 & 1.4 & 7 & 0.7 & 0.6 & 7 & $22.6 \%$ & $2.35[0.88,3.81]$ & & & \\
\hline Khorsand et al., (2013) [70] & 3.3 & 1.1 & 10 & 1.8 & 1.3 & 10 & $39.9 \%$ & $1.19[0.22,2.16]$ & & $\longrightarrow$ & \\
\hline Total $(95 \% \mathrm{Cl})$ & & & 28 & & & 28 & $100 \%$ & $1.8[1,2.59]$ & & & \\
\hline \multicolumn{9}{|c|}{$\begin{array}{l}\text { Heterogeneity: } \text { Tau }^{2}=0.17 ; \mathrm{Chi}^{2}=4, d f=3(P=0.26) ; i^{2}=25 \% \\
\text { Test for overall effect: } Z=4.44(P<0.00001)\end{array}$} & $\begin{array}{c}-2 \\
\text { Favours control }\end{array}$ & Favours st & $\begin{array}{lc}2 & 4 \\
\text { tem cell therapy }\end{array}$ \\
\hline
\end{tabular}

Figure 2. Forest plot showing combined periodontal ligament regeneration measures across the studies.

$\mathrm{SD}=$ standard deviation; $\mathrm{CI}=$ confidence interval; $\mathrm{df}=$ degrees of freedom .

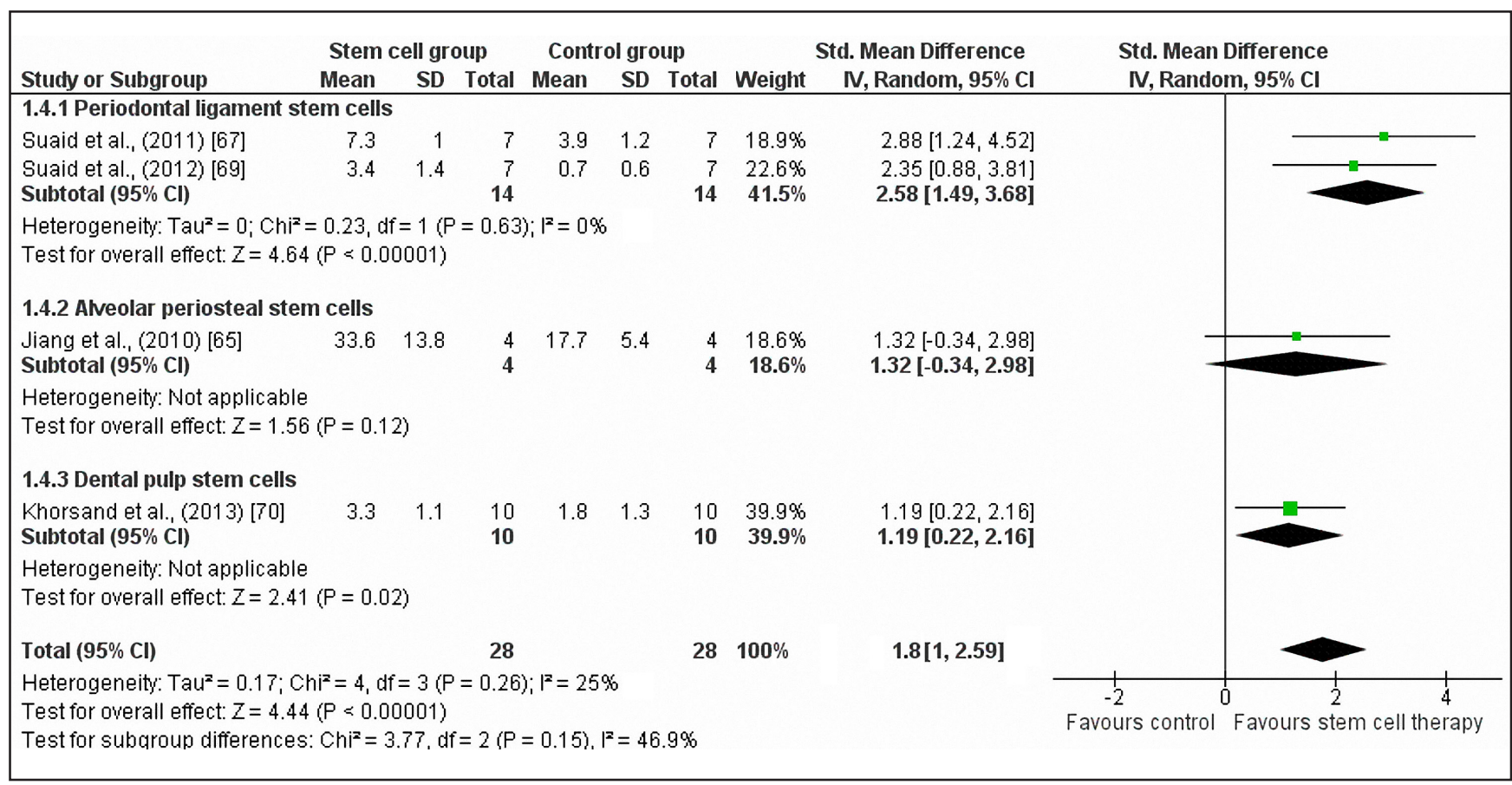

Figure 3. Forest plot for periodontal ligament regeneration measures stratified by stem cell type.

$\mathrm{SD}=$ standard deviation; $\mathrm{CI}=$ confidence interval; $\mathrm{df}=$ degrees of freedom.

\begin{tabular}{|c|c|c|c|c|c|c|c|c|c|c|c|}
\hline \multirow[b]{2}{*}{ Study or Subgroup } & \multicolumn{3}{|c|}{ Stem cell group } & \multicolumn{3}{|c|}{ Control group } & \multirow{2}{*}{ Weight } & \multirow{2}{*}{$\begin{array}{l}\text { Std. Mean Difference } \\
\text { IV, Random, } 95 \% \mathrm{Cl}\end{array}$} & \multirow{2}{*}{\multicolumn{2}{|c|}{$\begin{array}{c}\text { Std. Mean Difference } \\
\text { IV, Random, } 95 \% \mathrm{Cl}\end{array}$}} & \\
\hline & Mean & SD & Total & Mean & SD & Total & & & & & \\
\hline 1.3.1 12 weeks & & & & & & & & & & & \\
\hline Jiang et al., (2010) [65] & 33.6 & 13.8 & 4 & 17.7 & 5.4 & 4 & $18.6 \%$ & $1.32[-0.34,2.98]$ & 7 & & \\
\hline Suaid et al., (2011) [67] & 7.3 & 1 & 7 & 3.9 & 1.2 & 7 & $18.9 \%$ & $2.88[1.24,4.52]$ & & & \\
\hline Suaid et al., (2012) [69] & 3.4 & 1.4 & 7 & 0.7 & 0.6 & 7 & $22.6 \%$ & $2.35[0.88,3.81]$ & & & \\
\hline Subtotal $(95 \% \mathrm{Cl})$ & & & 18 & & & 18 & $60.1 \%$ & $2.2[1.29,3.11]$ & & & \\
\hline \multicolumn{12}{|c|}{$\begin{array}{l}\text { Heterogeneity: } \operatorname{Tau}^{2}=0 ; \mathrm{Chi}^{2}=1.79, \mathrm{df}=2(P=0.41) ; \mathrm{I}^{2}=0 \% \\
\text { Test for overall effect: } Z=4.73(P=0.00001)\end{array}$} \\
\hline \multicolumn{12}{|l|}{ 1.3.2 8 weeks } \\
\hline $\begin{array}{l}\text { Khorsand et al., (2013) [70] } \\
\text { Subtotal }(95 \% \mathrm{Cl})\end{array}$ & 3.3 & 1.1 & $\begin{array}{l}10 \\
10\end{array}$ & 1.8 & 1.3 & $\begin{array}{l}10 \\
10\end{array}$ & $\begin{array}{l}39.9 \% \\
39.9 \%\end{array}$ & $\begin{array}{l}1.19[0.22,2.16] \\
1.19[0.22,2.16]\end{array}$ & & & \\
\hline \multicolumn{12}{|c|}{$\begin{array}{l}\text { Heterogeneity: Not applicable } \\
\text { Test for overall effect: } Z=2.41(P=0.02)\end{array}$} \\
\hline Total $(95 \% \mathrm{Cl})$ & & & 28 & & & 28 & $100 \%$ & $1.8[1,2.59]$ & & & \\
\hline \multicolumn{9}{|c|}{$\begin{array}{l}\text { Heterogeneity: } \operatorname{Tau}^{2}=0.17 ; \mathrm{Chi}^{2}=4, \mathrm{df}=3(P=0.26) ; I^{2}=25 \% \\
\text { Test for overall effect: } Z=4.44(P=0.00001) \\
\text { Test for subqroup differences: } \mathrm{Chi}^{2}=2.21, \mathrm{df}=1(P=0.14), \mathrm{I}^{2}=54.7 \%\end{array}$} & $\begin{array}{cc}-2 & + \\
\text { Favours control } & 0\end{array}$ & Favours st & $\begin{array}{ll}2 & 4 \\
\text { stem cell therapy }\end{array}$ \\
\hline
\end{tabular}

Figure 4. Forest plot for periodontal ligament regeneration measures stratified by treatment duration.

$\mathrm{SD}=$ standard deviation; $\mathrm{CI}=$ confidence interval; $\mathrm{df}=$ degrees of freedom . 


\begin{tabular}{|c|c|c|c|c|c|c|c|c|c|c|c|}
\hline \multirow{2}{*}{ Study or Subgroup } & \multicolumn{3}{|c|}{ Stem cell group } & \multicolumn{3}{|c|}{ Control group } & \multirow{2}{*}{ Weight } & \multirow{2}{*}{$\begin{array}{l}\text { Std. Mean Difference } \\
\text { IV, Random, } 95 \% \mathrm{Cl}\end{array}$} & \multicolumn{2}{|c|}{$\begin{array}{l}\text { Std. Mean Difference } \\
\text { IV, Random, } 95 \% \mathrm{Cl}\end{array}$} & \\
\hline & \multicolumn{9}{|c|}{ 1.2.1 Bio-Oss } & & \\
\hline $\begin{array}{l}\text { Khorsand et al., (2013) [70] } \\
\text { Subtotal }(95 \% \mathrm{Cl})\end{array}$ & 3.3 & 1.1 & $\begin{array}{l}10 \\
10\end{array}$ & 1.8 & 1.3 & $\begin{array}{l}10 \\
10\end{array}$ & $\begin{array}{l}39.9 \% \\
39.9 \%\end{array}$ & $\begin{array}{l}1.19[0.22,2.16] \\
1.19[0.22,2.16]\end{array}$ & & & \\
\hline \multicolumn{12}{|c|}{$\begin{array}{l}\text { Heterogeneity: Not applicable } \\
\text { Test for overall effect: } Z=2.41(P=0.02)\end{array}$} \\
\hline \multicolumn{12}{|l|}{ 1.2.2 Collagen sponge } \\
\hline Suaid et al., (2011) [67] & 7.3 & 1 & 7 & 3.9 & 1.2 & 7 & $18.9 \%$ & $2.88[1.24,4.52]$ & & & \\
\hline $\begin{array}{l}\text { Suaid et al., (2012) [69] } \\
\text { Subtotal }(95 \% \text { Cl) }\end{array}$ & 3.4 & 1.4 & $\begin{array}{r}7 \\
14\end{array}$ & 0.7 & 0.6 & $\begin{array}{r}7 \\
14\end{array}$ & $\begin{array}{l}22.6 \% \\
41.5 \%\end{array}$ & $\begin{array}{r}2.35[0.88,3.81] \\
2.58[1.49,3.68]\end{array}$ & & & \\
\hline \multicolumn{12}{|c|}{$\begin{array}{l}\text { Heterogeneity: } \operatorname{Tau}^{2}=0 ; C h i^{2}=0.23, \mathrm{df}=1(P=0.63) ; I^{2}=0 \% \\
\text { Test for overall effect: } Z=4.64(P<0.00001)\end{array}$} \\
\hline \multicolumn{12}{|l|}{ 1.2.3 $\beta$-tricalcium phosphate } \\
\hline $\begin{array}{l}\text { Jiang et al., }(2010)[65] \\
\text { Subtotal }(95 \% \mathrm{Cl})\end{array}$ & 33.6 & 13.8 & $\begin{array}{l}4 \\
4\end{array}$ & 17.7 & 5.4 & $\begin{array}{l}4 \\
4\end{array}$ & $\begin{array}{l}18.6 \% \\
18.6 \%\end{array}$ & $\begin{array}{l}1.32[-0.34,2.98] \\
1.32[-0.34,2.98]\end{array}$ & & & \\
\hline \multicolumn{12}{|c|}{$\begin{array}{l}\text { Heterogeneity: Not applicable } \\
\text { Test for overall effect: } Z=1.56(P=0.12)\end{array}$} \\
\hline Total $(95 \% \mathrm{Cl})$ & & & 28 & & & 28 & $100 \%$ & $1.8[1,2.59]$ & & & \\
\hline $\begin{array}{l}\text { Heterogeneity: } \operatorname{Tau}^{2}=0.17 ; 0 \\
\text { Test for overall effect: } Z=4.4 \\
\text { Test for subaroup difference }\end{array}$ & $\begin{array}{l}h i^{2}=4, d \\
(P<0.0 \\
\therefore C h i^{2}=\end{array}$ & $\begin{array}{l}f=3(P \\
0001) \\
.77, d f\end{array}$ & $\begin{array}{l}=0.26 \\
=2(\mathrm{P}\end{array}$ & $\begin{array}{l}; F^{2}=25 \\
=0.15) .\end{array}$ & 6 & & & & $\begin{array}{cc}-1 & 1 \\
\text { Favours control } & 0\end{array}$ & Favours & $\begin{array}{l}2 \\
2\end{array}$ \\
\hline
\end{tabular}

Figure 5. Forest plot for periodontal ligament regeneration measures stratified by scaffold material type. $\mathrm{SD}=$ standard deviation; $\mathrm{CI}=$ confidence interval; $\mathrm{df}=$ degrees of freedom.

heterogeneity $\left(\mathrm{I}^{2}=80 \%\right.$; Chi-square $=61.21$; $\mathrm{P}<0.00001)$. All of the studies showed a net positive effect of stem cell therapy on alveolar bone treatment results. However 2 study subgroups reported no difference in treatment effect when compared with control groups. Nunez et al. [63] reported no difference in regenerative outcome when comparing cementum stem cell group (subgroup a) with the control group. However periodontal ligament stem cell group (subgroup b) produced a positive treatment outcome. Tsumanuma et al. [68] reported no positive alveolar bone regeneration results in alveolar periosteal stem cell group (subgroup b) and positive results in periodontal ligament stem cell subgroup (subgroup a). Overall the treatment significantly enhanced the regeneration of alveolar bone (SMD $1.47[95 \% \mathrm{CI}=0.7$ to 2.25$], \mathrm{P}=0.0002$ ) (Figure 6).

Subgroup analyses showed that there is a statistically significant difference in alveolar bone regeneration in relation to different stem cell types. Adipose tissue stem cells had a tendency to enhance the alveolar bone regeneration the most (SMD $2.71[95 \% \mathrm{CI}=$ 1.25 to 4.18$]$ ) however, only one study [61] formed this subgroup, and thus this result has low statistical power. Cementum stem cells did not affect the regeneration of alveolar bone, however, there was only one study [ $[\underline{63}]$ that used cementum stem cells, so this result might not represent the actual effect size that cementum stem cells have on alveolar bone regeneration (Figure 7). Treatment duration of 12 weeks had the biggest improvement for alveolar bone regeneration (SMD $1.87[95 \% \mathrm{CI}=0.65$ to 3.09]) however this result was not statistically significant when compared to 8 weeks of treatment (Figure 8). In the scaffold subgroup analysis there was a statistically significant difference between different scaffold materials $(P=0.009)$. $\beta$-tricalcium phosphate had the biggest effect on the alveolar bone regeneration (SMD $3.7[95 \% \mathrm{CI}=1.38$ to 6.01$]$ ) (Figure 9).

\section{Cementum regeneration}

Seven out of ten studies $[\underline{62}, \underline{63}, \underline{65}, \underline{67}, \underline{69-71}]$ reported data on the cementum regeneration. Pooled study results were of high heterogeneity $\left(\mathrm{I}^{2}=72 \%\right.$; Chisquare $=24.7 ; \mathrm{P}<0.00001)$. All of the studies reported positive treatment impact on cementum regeneration. Overall the treatment resulted in a statistically significant improvement in cementum regeneration when compared to the control group (SMD $2.25[95 \% \mathrm{CI}=1.21$ to 3.2$] ; \mathrm{P}<0.00001)$ (Figure 10).

Cementum stem cells had the biggest and significantly different effect size compared to other stem cell types (SMD $4.45[95 \% \mathrm{CI}=2.42$ to 6.48$] ; \mathrm{P}<0.00001)$ however there was only one study [63] in this subgroup thus this observation has a low statistical power (Figure 11).

There were no statistically significant differences among treatment and control groups in relation to different treatment duration and scaffold type (Figures 12 and 13). 


\begin{tabular}{|c|c|c|c|c|c|c|c|c|c|c|}
\hline \multirow[b]{2}{*}{ Study or Subgroup } & \multicolumn{3}{|c|}{ Stem cell group } & \multicolumn{3}{|c|}{ Control group } & \multicolumn{2}{|c|}{ Std. Mean Difference } & \multirow{2}{*}{\multicolumn{2}{|c|}{$\begin{array}{l}\text { Std. Mean Difference } \\
\text { IV, Random, } 95 \% \mathrm{Cl}\end{array}$}} \\
\hline & Mean & SD & Total & Mean & SD & Total & Weight & IV, Random, $95 \% \mathrm{Cl}$ & & \\
\hline Jiang et al., (2016) [62] & 29.1 & 6.6 & 9 & 15.2 & 4.9 & 9 & $7.9 \%$ & $2.28[1.03,3.53]$ & & \\
\hline Nuñez et al., (2012a) [63] & 2.6 & 0.4 & 8 & 2.6 & 0.7 & 8 & $8.5 \%$ & $0[-0.98,0.98]$ & & \\
\hline Nuñez et al., (2012b) [63] & 3.1 & 1.1 & 8 & 2.6 & 0.7 & 8 & $8.5 \%$ & $0.51[-0.49,1.51]$ & & \\
\hline Liu et al., (2008) [64] & 3.5 & 0.7 & 24 & 0.5 & 0.4 & 12 & $7.6 \%$ & $4.74[3.39,6.09]$ & & \\
\hline Jiang et al., (2010) [65] & 60.2 & 18.2 & 4 & 22.6 & 7.3 & 4 & $5.7 \%$ & $2.36[0.22,4.49]$ & & \\
\hline Park et al., (2011a) [66] & 82.8 & 7.9 & 8 & 47.9 & 13.4 & 8 & $7.1 \%$ & $3[1.45,4.55]$ & & \\
\hline Park et al., (2011b) [66] & 50.8 & 9.6 & 8 & 47.9 & 13.4 & 8 & $8.5 \%$ & $0.24[-0.75,1.22]$ & & \\
\hline Suaid et al., (2011) [67] & 9 & 2.3 & 7 & 7 & 0.6 & 7 & $8.1 \%$ & $1.11[-0.04,2.27]$ & & \\
\hline Tsumanuma et al., (2011a) [68] & 72.3 & 32.6 & 4 & 67.5 & 14.3 & 4 & $7.5 \%$ & $0.17[-1.22,1.56]$ & & \\
\hline Tsumanuma et al., (2011b) [68] & 67.6 & 21.6 & 4 & 67.5 & 14.3 & 4 & $7.5 \%$ & $0[-1.38,1.39]$ & & \\
\hline Suaid et al., (2012) [69] & 5.5 & 1.6 & 7 & 1.9 & 1 & 7 & $7.2 \%$ & $2.53[1,4.05]$ & & \\
\hline Khorsand et al., (2013) [70] & 3.6 & 1.1 & 10 & 3.1 & 0.8 & 10 & $8.7 \%$ & $0.5[-0.4,1.39]$ & & \\
\hline Tobita et al., (2013) [?1] & 63.6 & 8.6 & 8 & 40.3 & 7.6 & 8 & $7.3 \%$ & $2.71[1.25,4.18]$ & & \\
\hline Total $(95 \% \mathrm{Cl})$ & & & 109 & & & 97 & $100.0 \%$ & $1.47[0.7,2.25]$ & & \\
\hline \multicolumn{9}{|c|}{$\begin{array}{l}\text { Heterogeneity: } \operatorname{Tau}^{2}=1.6 ; \mathrm{Chi}^{2}=61.21, \mathrm{df}=12(\mathrm{P}<0.00001) ; \mathrm{F}^{\mathrm{F}}=80 \% \\
\text { Test for overall effect: } Z=3.72(P=0.0002)\end{array}$} & $\begin{array}{ll}-2 & 1 \\
\text { ivours control } & 0\end{array}$ & $\begin{array}{cc}2 & 4 \\
\text { Favours stem cell therapy }\end{array}$ \\
\hline
\end{tabular}

Figure 6. Forest plot showing combined alveolar bone regeneration measures across the studies.

$\mathrm{SD}=$ standard deviation; $\mathrm{CI}=$ confidence interval; $\mathrm{df}=$ degrees of freedom.

' $a$ ' and ' $b$ ' subscript letters next to the year of study: denotes different treatment groups within the same study.

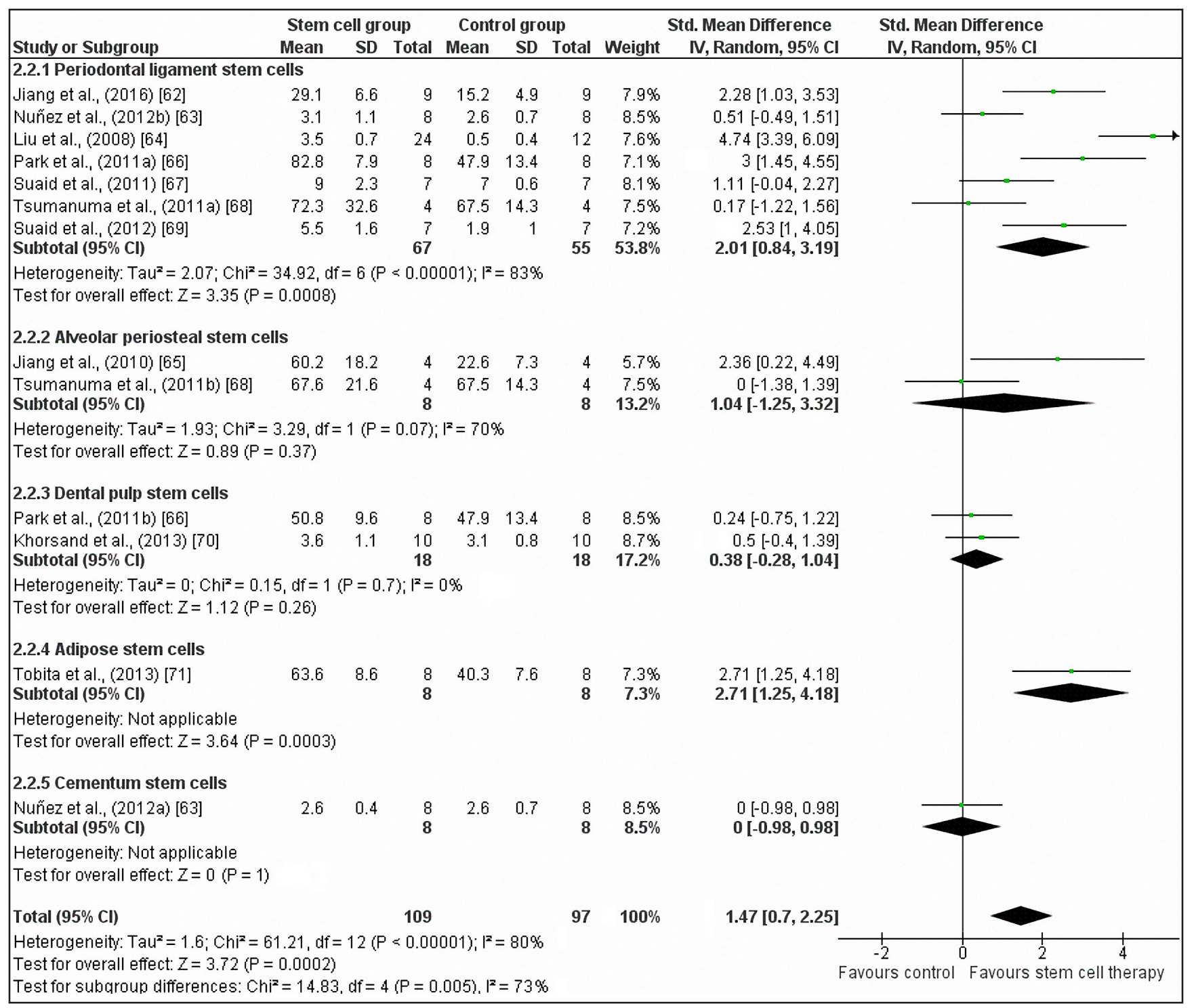

Figure 7. Forest plot for alveolar bone regeneration measures stratified by stem cell type.

$\mathrm{SD}=$ standard deviation; $\mathrm{CI}=$ confidence interval; $\mathrm{df}=$ degrees of freedom.

' $a$ ' and ' $b$ ' subscript letters next to the year of study: denotes different treatment groups within the same study. 


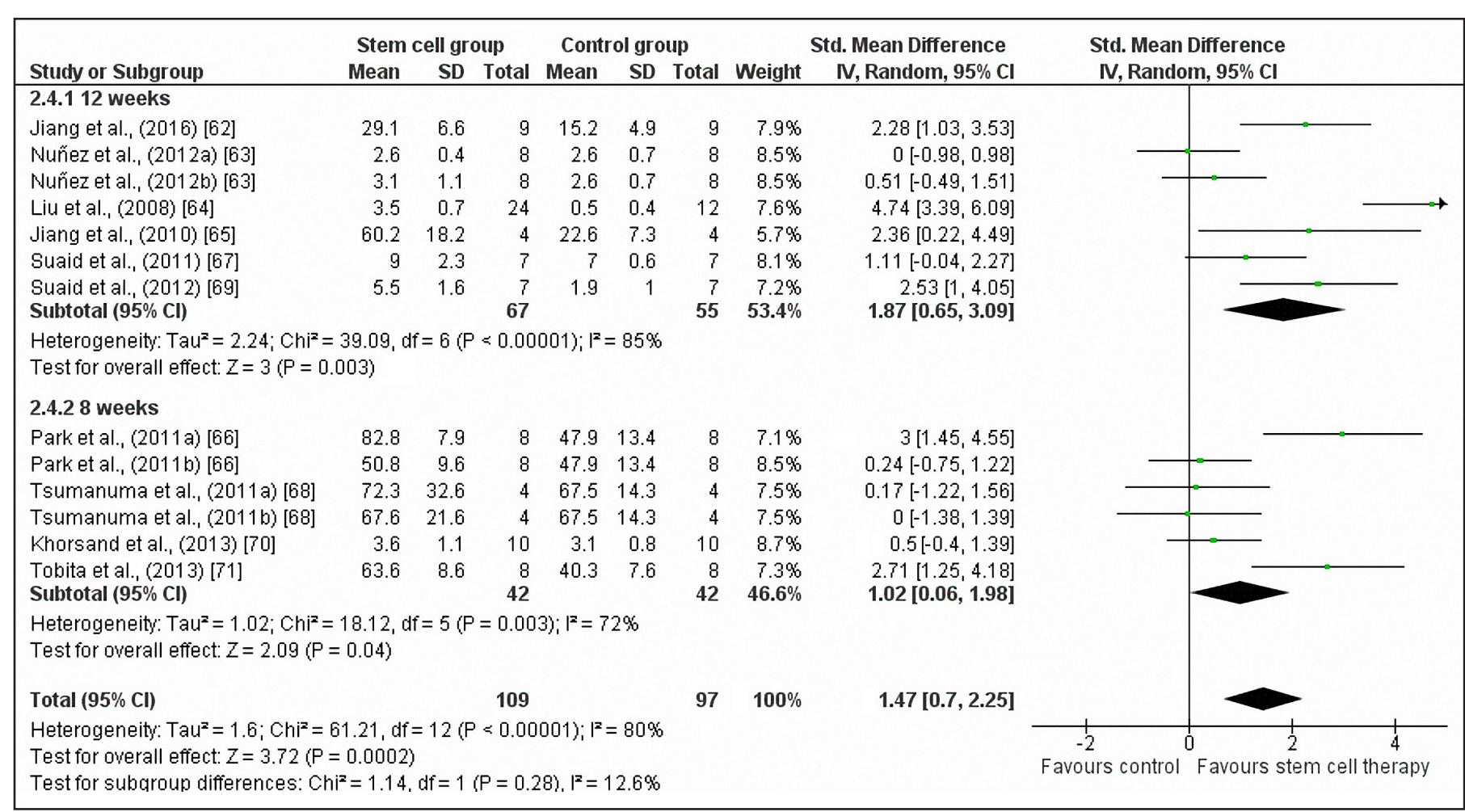

Figure 8. Forest plot for alveolar bone regeneration measures stratified by treatment duration.

$\mathrm{SD}=$ standard deviation; $\mathrm{CI}=$ confidence interval; $\mathrm{df}=$ degrees of freedom.

' $a$ ' and ' $b$ ' subscript letters next to the year of study: denotes different treatment groups within the same study.

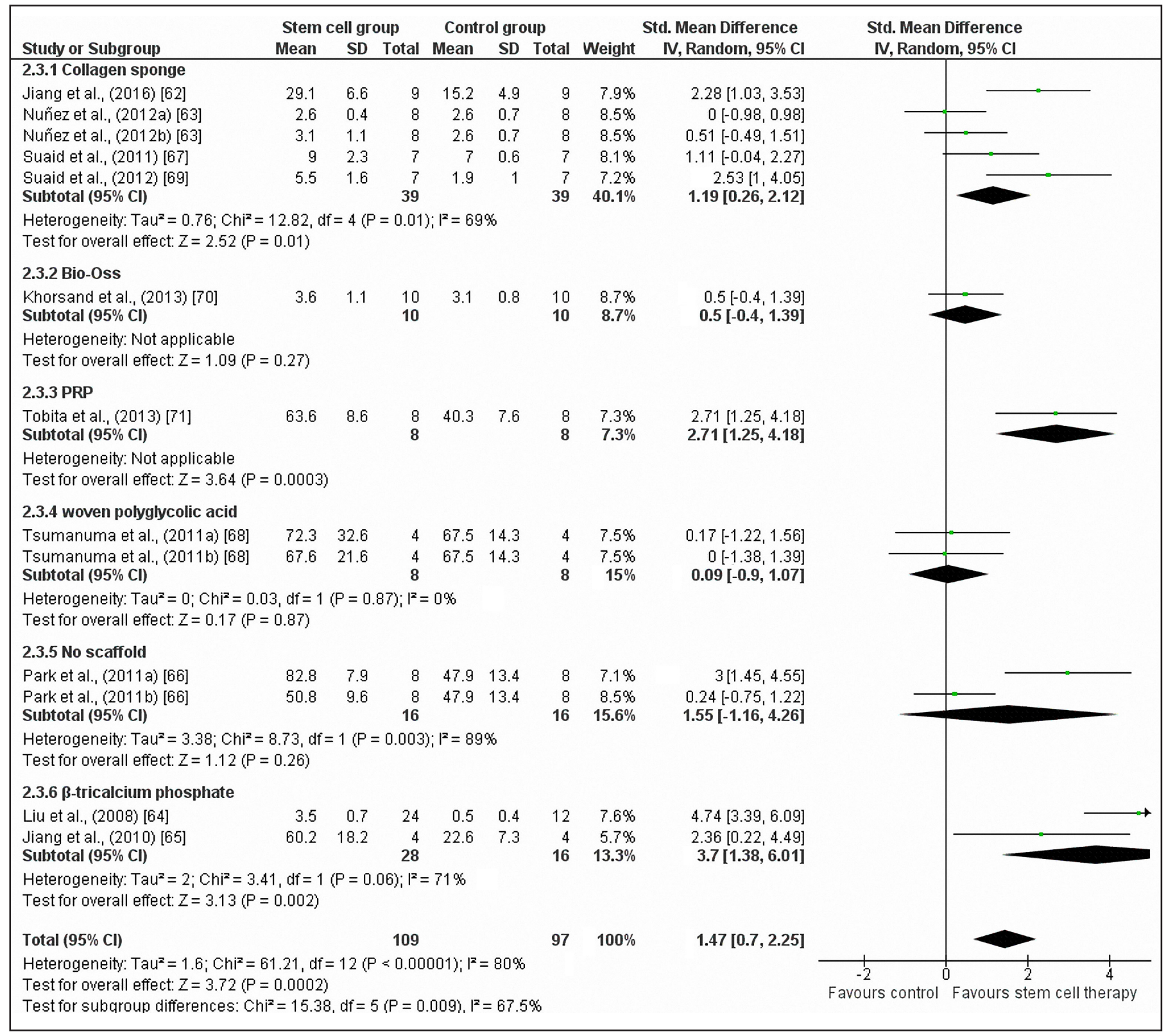

Figure 9. Forest plot for alveolar bone regeneration measures stratified by scaffold material.

$\mathrm{SD}=$ standard deviation; $\mathrm{CI}=$ confidence interval; $\mathrm{df}=$ degrees of freedom.

'a' and 'b' subscript letters next to the year of study: denotes different treatment groups within the same study.

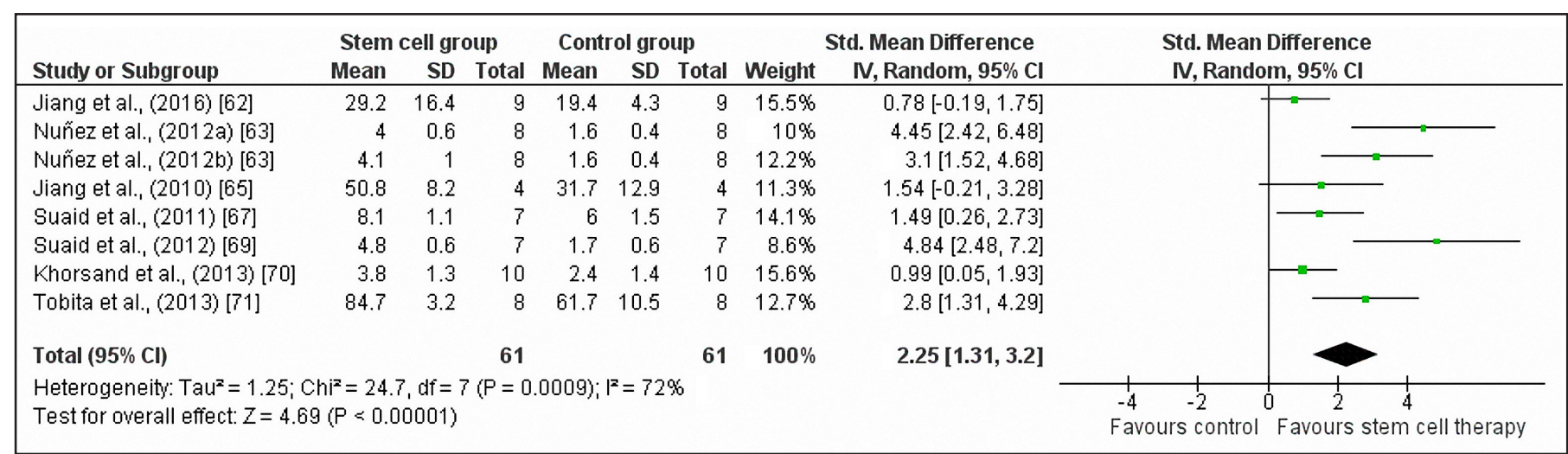

Figure 10. Forest plot showing combined cementum regeneration measures across the studies

$\mathrm{SD}=$ standard deviation; $\mathrm{CI}=$ confidence interval; $\mathrm{df}=$ degrees of freedom .

'a' and 'b' subscript letters next to the year of study: denotes different treatment groups within the same study. 


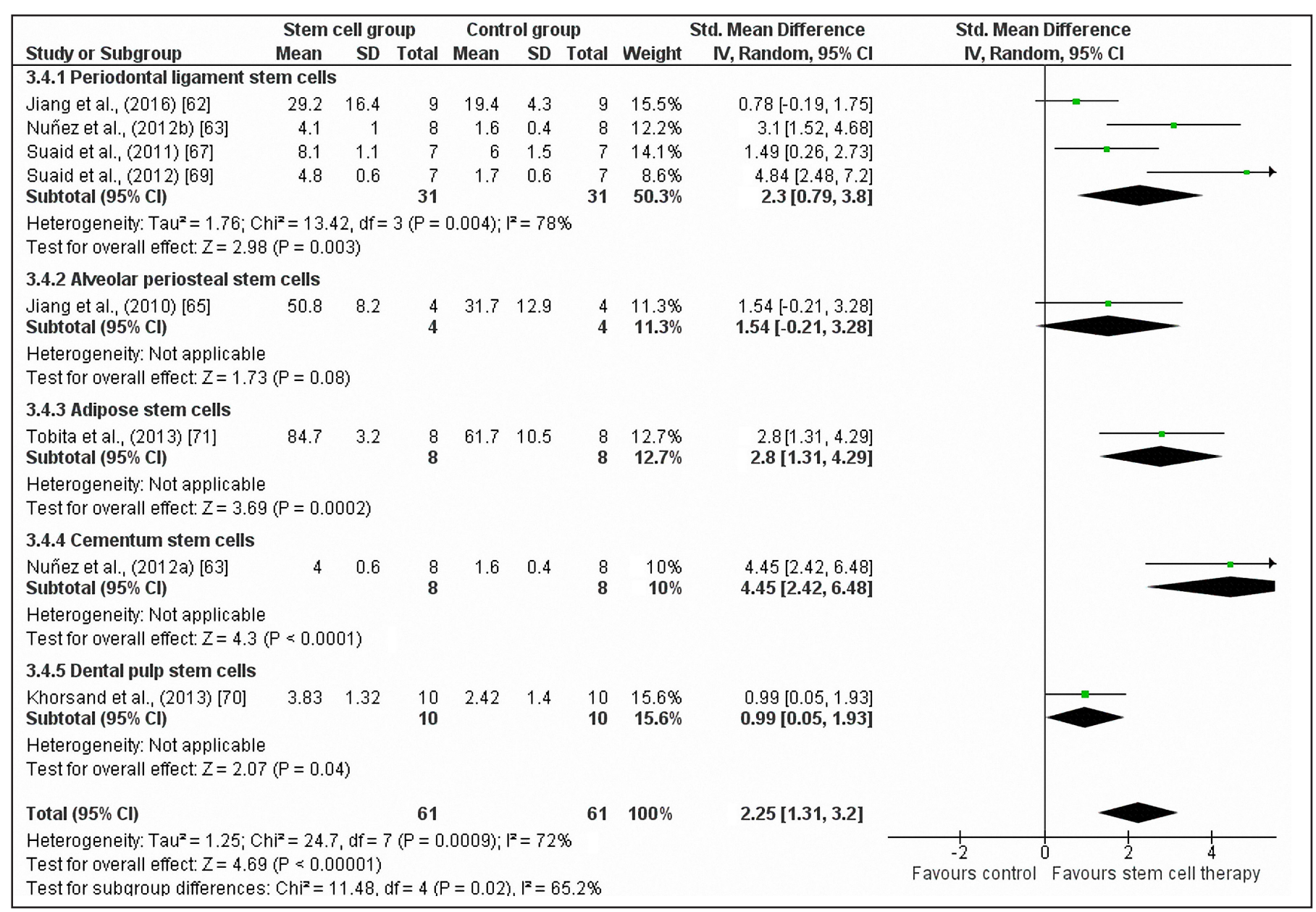

Figure 11.Forest plot for cementum regeneration measures stratified by stem cell type.

$\mathrm{SD}=$ standard deviation; $\mathrm{CI}=$ confidence interval; $\mathrm{df}=$ degrees of freedom

' $a$ ' and ' $b$ ' subscript letters next to the year of study: denotes different treatment groups within the same study.

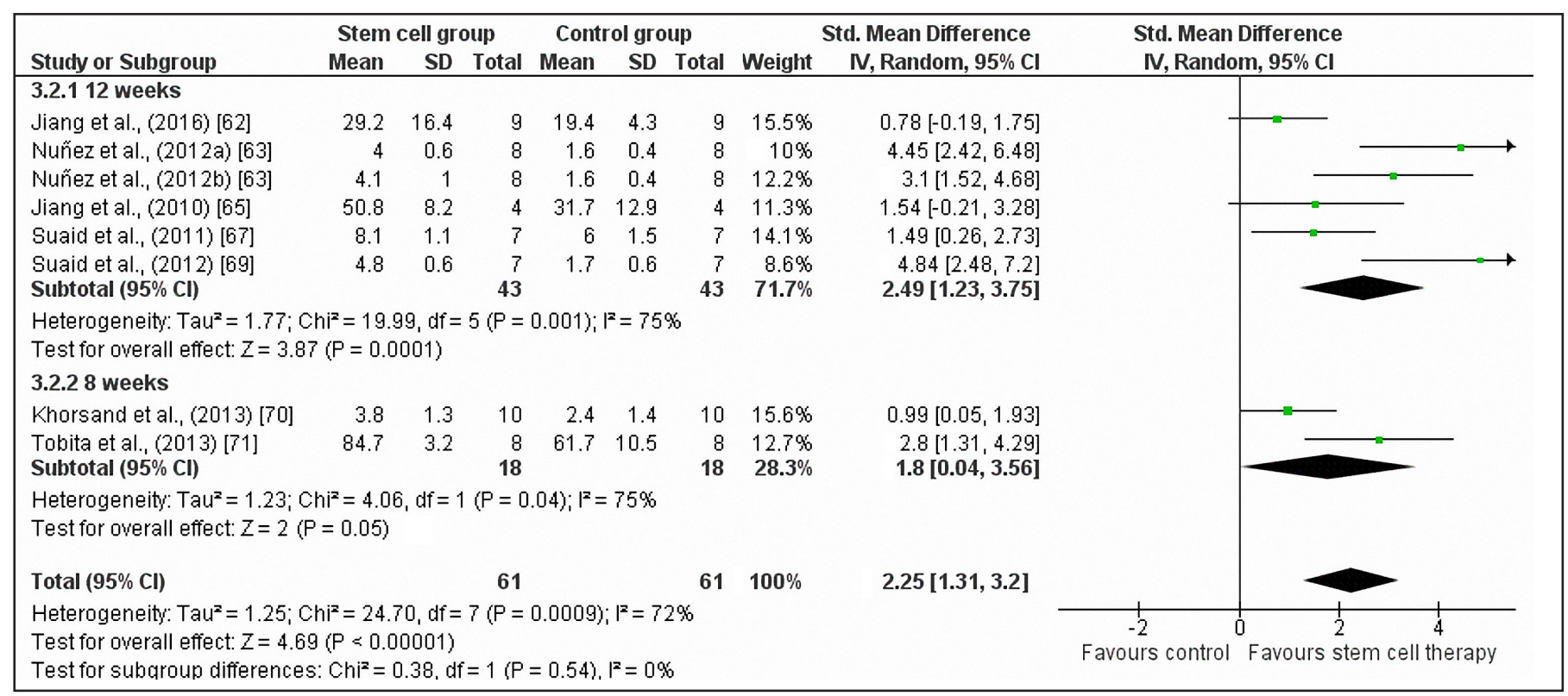

Figure 12.Forest plot for cementum regeneration measures stratified by treatment duration.

$\mathrm{SD}=$ standard deviation; $\mathrm{CI}=$ confidence interval; $\mathrm{df}$ = degrees of freedom.

' $a$ ' and ' $b$ ' subscript letters next to the year of study: denotes different treatment groups within the same study.

\begin{tabular}{|c|c|c|c|c|c|c|c|c|c|c|c|}
\hline \multirow{3}{*}{$\begin{array}{l}\text { Study or Subgroup } \\
3.3 .1 \text { Collagen sponge }\end{array}$} & \multicolumn{3}{|c|}{ Stem cell group } & \multicolumn{3}{|c|}{ Control group } & \multicolumn{2}{|c|}{ Std. Mean Difference } & \multirow{2}{*}{\multicolumn{2}{|c|}{$\begin{array}{l}\text { Std. Mean Difference } \\
\text { IV, Random, } 95 \% \mathrm{CI}\end{array}$}} & \\
\hline & Mean & SD & Total & Mean & SD & Total & Weight & IV, Random, $95 \% \mathrm{Cl}$ & & & \\
\hline & & & & & & & & & & & \\
\hline Jiang et al., (2016) [62] & 29.2 & 16.4 & 9 & 19.4 & 4.3 & 9 & $15.5 \%$ & $0.78[-0.19,1.75]$ & & & \\
\hline Nuñez et al., (2012a) [63] & 4 & 0.6 & 8 & 1.6 & 0.4 & 8 & $10 \%$ & $4.45[2.42,6.48]$ & & & \\
\hline Nuñez et al., (2012b) [63] & 4.1 & 1 & 8 & 1.6 & 0.4 & 8 & $12.2 \%$ & $3.1[1.52,4.68]$ & & & \\
\hline Suaid et al., (2011) [67] & 8.1 & 1.1 & 7 & 6 & 1.5 & 7 & $14.1 \%$ & $1.49[0.26,2.73]$ & & & \\
\hline $\begin{array}{l}\text { Suaid et al., (2012) [69] } \\
\text { Subtotal }(95 \% \mathrm{Cl})\end{array}$ & 4.8 & 0.6 & $\begin{array}{r}7 \\
39\end{array}$ & 1.7 & 0.6 & $\begin{array}{r}7 \\
39\end{array}$ & $\begin{array}{r}8.6 \% \\
60.3 \%\end{array}$ & $\begin{array}{r}4.84[2.48,7.2] \\
2.71[1.21,4.211\end{array}$ & & & \\
\hline \multicolumn{9}{|c|}{$\begin{array}{l}\text { Subtotal }(\mathbf{9 5} \% \mathrm{Cl}) \quad 39 \\
\text { Heterogeneity: } \operatorname{Tau}^{\mathbf{2}}=2.24 ; \mathrm{Chi}^{2}=19.79, \mathrm{df}=4(\mathrm{P}=0.0005) ; \mathrm{i}^{2}=80 \% \\
\text { Test for overall effect: } Z=3.53(\mathrm{P}=0.0004)\end{array}$} & & & \\
\hline \multicolumn{11}{|l|}{ 3.3.2 Bio-Oss } & \\
\hline $\begin{array}{l}\text { Khorsand et al., (2013) [70] } \\
\text { Subtotal }(95 \% \mathrm{Cl})\end{array}$ & 3.8 & 1.3 & $\begin{array}{l}10 \\
10\end{array}$ & 2.4 & 1.4 & $\begin{array}{l}10 \\
10\end{array}$ & $\begin{array}{l}15.6 \% \\
\mathbf{1 5 . 6} \%\end{array}$ & $\begin{array}{r}0.99[0.05,1.93] \\
\mathbf{0 . 9 9}[0.05, \mathbf{1 . 9 3}]\end{array}$ & & & \\
\hline \multicolumn{12}{|c|}{$\begin{array}{l}\text { Heterogeneity: Not applicable } \\
\text { Test for overall effect: } Z=2.07(P=0.04)\end{array}$} \\
\hline \multicolumn{12}{|c|}{ 3.3.3 PRP } \\
\hline $\begin{array}{l}\text { Tobita et al., (2013) [71] } \\
\text { Subtotal }(\mathbf{9 5} \% \mathbf{C l )}\end{array}$ & 84.7 & 3.2 & $\begin{array}{l}8 \\
8\end{array}$ & 61.7 & 10.5 & $\begin{array}{l}8 \\
8\end{array}$ & $\begin{array}{l}12.7 \% \\
12.7 \%\end{array}$ & $\begin{array}{r}2.8[1.31,4.29] \\
2.8[1.31,4.29]\end{array}$ & & & \\
\hline \multicolumn{12}{|c|}{$\begin{array}{l}\text { Heterogeneity: Not applicable } \\
\text { Test for overall effect: } Z=3.69(P=0.0002)\end{array}$} \\
\hline \multicolumn{12}{|l|}{ 3.3.4 $\beta$-tricalcium phosphate } \\
\hline $\begin{array}{l}\text { Jiang et al., (2010) [65] } \\
\text { Subtotal }(95 \% \mathrm{Cl})\end{array}$ & 50.8 & 8.2 & $\begin{array}{l}4 \\
4\end{array}$ & 31.7 & 12.9 & $\begin{array}{l}4 \\
4\end{array}$ & $\begin{array}{l}11.3 \% \\
\mathbf{1 1 . 3} \%\end{array}$ & $\begin{array}{l}1.54[-0.21,3.28] \\
\mathbf{1 . 5 4}[-0.21,3.28]\end{array}$ & & & \\
\hline \multicolumn{12}{|c|}{$\begin{array}{l}\text { Heterogeneity: Not applicable } \\
\text { Test for overall effect: } Z=1.73(P=0.08)\end{array}$} \\
\hline Total $(95 \% \mathrm{Cl})$ & & & 61 & & & 61 & $100 \%$ & $2.25[1.31,3.2]$ & & & \\
\hline \multicolumn{9}{|c|}{$\begin{array}{l}\text { Heterogeneity: } \mathrm{Tau}^{2}=1.25 ; \mathrm{Ch}^{2}=24.70, \mathrm{df}=7(\mathrm{P}=0.0009) ; \mathrm{I}^{2}=72 \% \\
\text { Test for overall effect: } Z=4.69(\mathrm{P}=0.00001) \\
\text { Test for subaroun differences: } \mathrm{Ch} \mathrm{z}^{2}=6.03 \mathrm{df}=3(\mathrm{P}=0.11) \mathrm{I}^{\mathrm{z}}=50.3 \%\end{array}$} & $\begin{array}{cl}-2 & -2 \\
\text { Favours control } & 0\end{array}$ & $\begin{array}{lr}+1 \\
0\end{array}$ & $\begin{array}{l}4 \\
2 \\
\text { stem cell therapy }\end{array}$ \\
\hline
\end{tabular}

Figure 13.Forest plot for cementum regeneration measures stratified by scaffold material.

$\mathrm{SD}=$ standard deviation; $\mathrm{CI}=$ confidence interval; $\mathrm{df}=$ degrees of freedom .

' $a$ ' and ' $b$ ' subscript letters next to the year of study: denotes different treatment groups within the same study. 


\section{Summary of the results}

The stem cell regenerative therapy made a statistically significant difference to the periodontal tissue regeneration when compared to the control groups. Such therapy seemed to make the biggest influence to the regeneration of cementum (SMD 2.25 [95\% $\mathrm{CI}=1.31$ to 3.2]) and the smallest influence was made to alveolar bone (SMD 1.47 [95\% CI $=0.7$ to 2.25$]$ ) the effect size for periodontal ligament regeneration was (SMD 1.80 [95\% CI $=1$ to 2.59]). The study data seemed to be highly heterogeneous on both cementum and alveolar bone regeneration results. Subgroup analyses did not explain the possible cause of this heterogeneity. Subgroup analyses showed a statistically significant difference in alveolar bone and cementum regeneration groups based on treatment duration. However, this result might be biased due to a small number of studies ( 1 - 2 studies) grouped in the latter subgroup meta-analyses.

\section{DISCUSSION}

Regeneration of the periodontal ligament, cementum and alveolar bone has been of significant clinical interest in scientific literature. Although there have been some advances made in this field, there is still no optimal treatment for periodontal tissue regeneration. This study contributes evidence of mesenchymal stem cell efficacy for the regeneration of animal periodontal defects. Results of this study show that mesenchymal stem cell-based therapy can be expected to result in a favourable clinical outcome for periodontal tissue regeneration. These results are consistent with previously published systematic reviews [16-18].

Despite experimental evidence showing that periodontal regeneration can occur in an experimental setting, predictable regeneration in humans remains an elusive clinical goal [18]. For periodontal regeneration to occur, the potential of stem/progenitor cells to recapitulate periodontal development needs to be studied. Although cytotherapeutic approach to periodontal regeneration is in its beginning stages, the future for this kind of regenerative therapy looks very encouraging $[16,17]$. Nonetheless, before this becomes a routine clinical procedure, a number of relevant topics need to be assessed, such as: designing appropriate cell delivery matrices, understanding the immunogenic and immunoregulatory properties of these cells, defining which cells can have the greatest effect on tissue regeneration [72]. Another consideration would be the cost to benefit ratio. Given that periodontitis is not a terminal disease, any therapy should be entirely justified. The first step in this process has been to undertake studies in preclinical animal models. As our study has shown, stem cell therapy can be beneficial regarding periodontal tissue regeneration in animal models. The second step is the undertaking of human studies which has ethical implications associated with harvesting biopsy specimens from living human subjects. Researchers have already attempted to regenerate periodontal defects in humans [73-76]. However, all of these studies utilized noninvasive methods to measure tissue regeneration levels: radiologic evaluation, probing depth, clinical attachment level, and gingival recession evaluation. Chen et al. [74] concluded that implantation of autologous periodontal ligament stem cells into periodontal intrabony defects did not produce any noteworthy adverse effects. Zanwar et al. [75] noted that stem cell therapy is beneficial in the treatment for gingival recession. Provided that future researchers would adhere to similar study protocols, profound insight into this treatment method could be made. Considering current scientific trends and advances, it would seem that it is now appropriate to consider progressing from preclinical animal studies to human studies.

\section{Limitations of the study}

Selected studies showed a significant amount of heterogeneity in the meta-analysis. Although a high level of heterogeneity was expected because of the variety of methodologies, and clinical variations. This observation was also noted in other systematic reviews studying periodontal tissue regeneration utilizing stem cell therapy [16-18]. Pooled studies varied in stem cell type, scaffold material and the duration of treatment. Thus, data from this metaanalysis should be interpreted with caution. There is scientific evidence that scaffold material can increase or decrease the speed and quality of periodontal tissue regeneration results [므, $\underline{77}]$. Different studies also reported the regeneration of two or only a single tissue component of the periodontal complex (alveolar bone, cementum or the periodontal ligament). Studies were divided into a number of subgroups stratified by different stem cell types, treatment duration and scaffold materials in an attempt to explain the present heterogeneity among results. As a result, some subgroups pooled only 1 to 2 studies. Hence the data from this meta-analysis has low statistical power. Nonetheless, the overall positive impact of stem cell treatment was apparent as the majority of the studies demonstrated a statistically significant improvement in periodontal complex tissue regeneration measures. 


\section{CONCLUSIONS}

Current scientific data is unanimous on the fact that stem cell therapy has a positive impact on periodontal tissue complex regeneration. Such therapy has the most significant on cementum regeneration meanwhile alveolar bone regeneration is influenced by the least amount. Preclinical data also show that the type of stem cells used in therapeutic procedures is a significant factor considering alveolar bone and cementum tissue regeneration results while scaffold materials are a significant factor in alveolar bone regenerative therapy. Regarding treatment duration, the greatest effect on periodontal tissue regeneration was observed after 12 weeks. However more and less diverse preclinical studies are needed to have higher statistical power in future meta-analyses.

\section{ACKNOWLEDGMENTS AND DISCLOSURE STATEMENTS}

The authors report no conflicts of interest related to this study.

\section{REFERENCES}

1. Nazir MA. Prevalence of periodontal disease, its association with systemic diseases and prevention. Int J Health Sci (Qassim). 2017 Apr-Jun;11(2):72-80. [Medline: 28539867] [PMC free article: 5426403]

2. Tonetti MS, Jepsen S, Jin L, Otomo-Corgel J. Impact of the global burden of periodontal diseases on health, nutrition and wellbeing of mankind: A call for global action. J Clin Periodontol. 2017 May;44(5):456-462. [Medline: 28419559] [doi: 10.1111/jepe.12732]

3. Jansson H, Wahlin $\AA$, Johansson V, Åkerman S, Lundegren N, Isberg PE, Norderyd O. Impact of periodontal disease experience on oral health-related quality of life. J Periodontol. 2014 Mar;85(3):438-45. [Medline: 23895254] [doi: 10.1902/jop.2013.130188]

4. Ansari Moghadam S, Abdollahi Z, Risbaf Fakour S, Ansari Moghaddam A, Kiany F, Damani N. The Relationship Between Periodontal Disease and Public Health: A Population-Based Study. Glob J Health Sci. 2015 Nov 18;8(7):110-5. [Medline: 26925886] [PMC free article: 4965638] [doi: 10.5539/gjhs.v8n7p110]

5. Sculean A, Nikolidakis D, Nikou G, Ivanovic A, Chapple IL, Stavropoulos A. Biomaterials for promoting periodontal regeneration in human intrabony defects: a systematic review. Periodontol 2000. 2015 Jun;68(1):182-216. [Medline: 25867987] [doi: 10.1111/prd.12086]

6. Roselló-Camps À, Monje A, Lin GH, Khoshkam V, Chávez-Gatty M, Wang HL, Gargallo-Albiol J, HernandezAlfaro F. Platelet-rich plasma for periodontal regeneration in the treatment of intrabony defects: a meta-analysis on prospective clinical trials. Oral Surg Oral Med Oral Pathol Oral Radiol. 2015 Nov;120(5):562-74. [Medline: 26453383] [doi: 10.1016/j.0000.2015.06.035]

7. Kao RT, Nares S, Reynolds MA. Periodontal regeneration - intrabony defects: a systematic review from the AAP Regeneration Workshop. J Periodontol. 2015 Feb;86(2 Suppl):S77-104. [Medline: 25216204] [doi: 10.1902/jop.2015.130685]

8. Seshima F, Aoki H, Takeuchi T, Suzuki E, Irokawa D, Makino-Oi A, Sugito H, Tomita S, Saito A. Periodontal regenerative therapy with enamel matrix derivative in the treatment of intrabony defects: a prospective 2-year study. BMC Res Notes. 2017 Jul 6;10(1):256. [Medline: 28683765] [PMC free article: 5501118] [doi: 10.1186/s13104-017-2572-2]

9. Yoshida T, Washio K, Iwata T, Okano T, Ishikawa I. Current status and future development of cell transplantation therapy for periodontal tissue regeneration. Int J Dent. 2012;2012:307024. [Medline: 22315604] [doi: 10.1155/2012/307024]

10. Liu J, Yu F, Sun Y, Jiang B, Zhang W, Yang J, Xu GT, Liang A, Liu S. Concise reviews: Characteristics and potential applications of human dental tissue-derived mesenchymal stem cells. Stem Cells. 2015 Mar;33(3):627-38. [Medline: 25447379] [doi: 10.1002/stem.1909]

11. Han J, Menicanin D, Marino V, Ge S, Mrozik K, Gronthos S, Bartold PM. Assessment of the regenerative potential of allogeneic periodontal ligament stem cells in a rodent periodontal defect model. J Periodontal Res. 2014 Jun;49(3): 333-45. [Medline: 23841948] [doi: 10.1111/jre.12111]

12. Estrela C, Alencar AH, Kitten GT, Vencio EF, Gava E. Mesenchymal stem cells in the dental tissues: perspectives for tissue regeneration. Braz Dent J. 2011;22:91-98. [Medline: 21537580] [doi: 10.1590/S0103-64402011000200001]

13. Lei M, Li K, Li B, Gao LN, Chen FM, Jin Y. Mesenchymal stem cell characteristics of dental pulp and periodontal ligament stem cells after in vivo transplantation. Biomaterials. 2014 Aug;35(24):6332-43. [Medline: 24824581] [doi: 10.1016/j.biomaterials.2014.04.071]

14. Bronckaers A, Hilkens P, Martens W, Gervois P, Ratajczak J, Struys T, Lambrichts I. Mesenchymal stem/stromal cells as a pharmacological and therapeutic approach to accelerate angiogenesis. Pharmacol Ther. 2014 Aug;143(2):181-96. [Medline: 24594234] [doi: 10.1016/j.pharmthera.2014.02.013] 
15. Dangaria SJ, Ito $\mathrm{Y}$, Luan $\mathrm{X}$, Diekwisch TG. Successful periodontal ligament regeneration by periodontal progenitor preseeding on natural tooth root surfaces. Stem Cells Dev. 2011;20(10):1659-68. [Medline: 21250830] [doi: $10.1089 / \mathrm{scd} .2010 .0431]$

16. Monsarrat P, Vergnes JN, Nabet C, Sixou M, Snead ML, Planat-Bénard V, Casteilla L, Kémoun P. Concise review: mesenchymal stromal cells used for periodontal regeneration: a systematic review. Stem Cells Transl Med. 2014;3(6): 768-74. [Medline: 24744392] [doi: 10.5966/sctm.2013-0183]

17. Trofin EA, Monsarrat P, Kémoun P. Cell therapy of periodontium: from animal to human? Front Physiol. 2013;4:325. [Medline: 24298258] [doi: 10.3389/fphys.2013.00325]

18. Hynes K, Menicanin D, Gronthos S, Bartold PM. Clinical utility of stem cells for periodontal regeneration. Periodontol 2000. 2012;59:203-227. [Medline: 22507067] [doi: 10.1111/j.1600-0757.2012.00443.x]

19. Tassi SA, Sergio NZ, Misawa MYO, Villar CC. Efficacy of stem cells on periodontal regeneration: Systematic review of pre-clinical studies. J Periodont Res. 2017;52(5):793-812. [Medline: 28394043] [doi: 10.1111/jre.12455]

20. Bright R, Hynes K, Gronthos S, Bartold PM. Periodontal ligament-derived cells for periodontal regeneration in animal models: a systematic review. J Periodont Res. 2015;50(2):160-72. [Medline: 24965968] [doi: 10.1111/jre.12205]

21. Moher D, Liberati A, Tetzlaff J, Altman DG. Preferred reporting items for systematic reviews and meta-analyses: the PRISMA statement. PLoS Med. 2009;6(7):e1000097. [Medline: 19622511] [doi: 10.1371/journal.pmed.1000097]

22. Higgins JP1, Altman DG, Gøtzsche PC, Jüni P, Moher D, Oxman AD, Savovic J, Schulz KF, Weeks L, Sterne JA. The Cochrane Collaboration's tool for assessing risk of bias in randomised trials. BMJ. 2011;343:d5928. [Medline: 22008217] [doi: 10.1136/bmj.d5928]

23. Qiu G, Shi Z, Xu HHK. Bone regeneration in minipigs via calcium phosphate cement scaffold delivering autologous bone marrow mesenchymal stem cells and platelet-rich plasma. J Tissue Eng Regen Med. 2018;12(2):e937-e948. [Medline: 28102000] [doi: 10.1002/term.2416]

24. Takewaki M, Kajiya M, Takeda K, Sasaki S, Motoike S, Komatsu N, Matsuda S, Ouhara K, Mizuno N, Fujita T, Kurihara H. MSC/ECM Cellular Complexes Induce Periodontal Tissue Regeneration. J Dent Res. 2017;96(9):984-991. [Medline: 28521114] [doi: 10.1177/0022034517708770]

25. Hynes K, Menicanin D, Han J, Marino V, Mrozik K, Gronthos S, Bartold PM. Mesenchymal stem cells from iPS cells facilitate periodontal regeneration. J Dent Res. 2013;92(9):833-9. [Medline: 23884555] [doi: 10.1177/0022034513498258]

26. Yan J, Zhang C, Zhao Y, Cao 2, Wu K, Zhao L, Zhang Y. Non-viral oligonucleotide antimiR-138 delivery to mesenchymal stem cell sheets and the effect on osteogenesis. Biomaterials. 2014;35(27):7734-49. [Medline: 24952983] [doi: 10.1016/j.biomaterials.2014.05.089]

27. Fawzy el-sayed KM, Paris S, Becker ST. Periodontal regeneration employing gingival margin-derived stem/progenitor cells: an animal study. J Clin Periodontol. 2012;39(9):861-70. [Medline: 22694281] [doi: 10.1111/j.1600-051X.2012.01904.x]

28. Jiang J, Wu X, Lin M, Doan N, Xiao Y, Yan F. Application of autologous cells for the regeneration of class III furcation defects in Beagle dogs. Cytotechnology. 2010;62(3):235-43. [Medline: 22694281] [doi: 10.1007/s10616-010-9284-y]

29. Wei N, Gong P, Liao D, Yang X, Li X, Liu Y, Yuan Q, Tan Z. Auto-transplanted mesenchymal stromal cell fate in periodontal tissue of beagle dogs. Cytotherapy. 2010;12(4):514-21. [Medline: 20370352] [doi: 10.3109/14653241003709702]

30. Pieri F, Lucarelli E, Corinaldesi G, Fini M, Aldini NN, Giardino R, Donati D, Marchetti C. Effect of mesenchymal stem cells and platelet-rich plasma on the healing of standardized bone defects in the alveolar ridge: a comparative histomorphometric study in minipigs. J Oral Maxillofac Surg. 2009;67(2):265-72. [Medline: 19138598] [doi: 10.1016/j.joms.2008.06.036]

31. Zhang L, Wang P, Mei S, Li C, Cai C, Ding Y. In vivo alveolar bone regeneration by bone marrow stem cells/fibrin glue composition. Arch Oral Biol. 2012;57(3):238-44. [Medline: 21924703] [doi: 10.1016/j.archoralbio.2011.08.025]

32. Chung VH, Chen AY, Kwan CC, Chen PK, Chang SC. Mandibular alveolar bony defect repair using bone morphogenetic protein 2-expressing autologous mesenchymal stem cells. J Craniofac Surg. 2011;22(2):450-4. [Medline: 21403565] [doi: 10.1097/SCS.0b013e3182077de9]

33. Simsek SB, Keles GC, Baris S, Cetinkaya BO. Comparison of mesenchymal stem cells and autogenous cortical bone graft in the treatment of class II furcation defects in dogs. Clin Oral Investig. 2012;16(1):251-8. [Medline: 21086003] [doi: 10.1007/s00784-010-0486-7]

34. Li YF, Yan FH, Zhong Q, Zhao X. Effect of hBMP-7 gene modified bone marrow stromal cells on periodontal tissue regeneration. Zhonghua Yi Xue Za Zhi. 2010;90(20):1427-30. [Medline: 20646636] [doi: 10.3760/cma.j.issn.0376-2491.2010.20.017]

35. Du J, Shan Z, Ma P, Wang S, Fan Z. Allogeneic bone marrow mesenchymal stem cell transplantation for periodontal regeneration. J Dent Res. 2014;93(2):183-8. [Medline: 24226426] [doi: 10.1177/0022034513513026]

36. Akita D, Kano K, Saito-tamura Y, Mashimo T, Sato-Shionome M, Tsurumachi N, Yamanaka K, Kaneko T, Toriumi T, Arai Y, Tsukimura N, Matsumoto T, Ishigami T, Isokawa K, Honda M. Use of Rat Mature Adipocyte-Derived Dedifferentiated Fat Cells as a Cell Source for Periodontal Tissue Regeneration. Front Physiol. 2016;7:50. [Medline: 26941649] [doi: 10.3389/fphys.2016.00050]

37. Yu N, Bronckers AL, Oortgiesen DA, Yan X, Jansen JA, Yang F, Walboomers XF. Periodontal cell implantation contributes to the regeneration of the periodontium in an indirect way. Tissue Eng Part A. 2015;21(1-2):166-73. [Medline: 25077766] [doi: $10.1089 /$ ten.tea.2014.0151] 
38. Gimble JM, Bunnell BA, Frazier T, Rowan B, Shah F, Thomas-Porch C, Wu X. Adipose-derived stromal/stem cells: A primer. Organogenesis. 2013;9(1):3-10. [Medline: 23538753] [doi: 10.4161/org. 24279]

39. Sugawara A, Sato S. Application of dedifferentiated fat cells for periodontal tissue regeneration. Hum Cell. 2014;27(1): 12-21. [Medline: 24068600] [doi: 10.1007/s13577-013-0075-6]

40. Du M, Zhu T, Duan X, Ge S, Li N, Sun Q, Yang P. Acellular dermal matrix loading with bFGF achieves similar acceleration of bone regeneration to BMP-2 via differential effects on recruitment, proliferation and sustained osteodifferentiation of mesenchymal stem cells. Mater Sci Eng C Mater Biol Appl. 2017;70(Pt 1):62-70. [Medline: 27770935] [doi: 10.1016/j.msec.2016.08.049]

41. Tobita M, Uysal AC, Ogawa R, Hyakusoku H, Mizuno H. Periodontal tissue regeneration with adipose-derived stem cells. Tissue Eng Part A. 2008;14(6):945-53. [Medline: 18558814] [doi: 10.1089/ten.tea.2007.0048]

42. Zhou W, Zhao CH, Mei LX. Effect of the compound of poly lactic-co-glycolic acid and bone marrow stromal cells modified by osteoprotegerin gene on the periodontal regeneration in Beagle dog periodontal defects. Hua Xi Kou Qiang Yi Xue Za Zhi. 2010;28(3):324-9. [Medline: 20635668] [doi: 10.1089/ten.tea.2007.0048]

43. Yamada Y, Ito K, Nakamura S, Ueda M, Nagasaka T. Promising cell-based therapy for bone regeneration using stem cells from deciduous teeth, dental pulp, and bone marrow. Cell Transplant. 2011;20(7):1003-13. [Medline: 21054950] [doi: $10.3727 / 096368910 X 539128]$

44. Yu N, Oortgiesen DA, Bronckers AL, Yang F, Walboomers XF, Jansen JA. Enhanced periodontal tissue regeneration by periodontal cell implantation. J Clin Periodontol. 2013;40(7):698-706. [Medline: 23675871] [doi: 10.1111/jepe.12113]

45. Gonçalves F, De moraes MS, Ferreira LB, Carreira AC, Kossugue PM, Boaro LC, Bentini R, Garcia CR, Sogayar MC, Arana-Chavez VE, Catalani LH. Combination of Bioactive Polymeric Membranes and Stem Cells for Periodontal Regeneration: In Vitro and In Vivo Analyses. PLoS ONE. 2016;11(3):e0152412. [Medline: 27031990] [doi: 10.1371/journal.pone.0152412]

46. Tang HN, Xia Y, Xu J, Tian BM, Zhang XY, Chen FM. Assessment of cellular materials generated by co-cultured 'inflamed' and healthy periodontal ligament stem cells from patient-matched groups. Exp Cell Res. 2016;346(1):119-29. [Medline: 27237095] [doi: 10.1016/j.yexcr.2016.05.003]

47. Yang C, Lee JS, Jung UW, Seo YK, Park JK, Choi SH. Periodontal regeneration with nano-hyroxyapatite-coated silk scaffolds in dogs. J Periodontal Implant Sci. 2013;43(6):315-22. [Medline: 24455445] [doi: 10.5051/jpis.2013.43.6.315]

48. Xu Q, Li B, Yuan L, Dong Z, Zhang H, Wang H, Sun J, Ge S, Jin Y. Combination of platelet-rich plasma within periodontal ligament stem cell sheets enhances cell differentiation and matrix production. J Tissue Eng Regen Med. 2017;11(3): 627-636. [Medline: 25186188] [doi: 10.1002/term.1953]

49. Iwasaki K, Komaki M, Yokoyama N, Tanaka Y, Taki A, Honda I, Kimura Y, Takeda M, Akazawa K, Oda S, Izumi Y, Morita I. Periodontal regeneration using periodontal ligament stem cell-transferred amnion. Tissue Eng Part A. 2014; 20(3-4):693-704. [Medline: 24032400] [doi: 10.1089/ten.tea.2013.0017]

50. Duan X, Tu Q, Zhang J, Ye J, Sommer C, Mostoslavsky G, Kaplan D, Yang P, Chen J. Application of induced pluripotent stem (iPS) cells in periodontal tissue regeneration. J Cell Physiol. 2011;226(1):150-7. [Medline: 20658533] [doi: $10.1002 /$ jep.22316]

51. Sadeghi D, Nazarian H, Nojehdehian H. Adipose-derived stem cells combined with beta-tricalcium phosphate: a novel possible strategy for periodontal defects regeneration. Med Hypotheses. 2014;82(1):54-6. . [Medline: 24284062] [doi: 10.1016/j.mehy.2013.11.003]

52. Tobita M, Mizuno H. Adipose-derived stem cells and platelet-rich plasma: the keys to functional periodontal tissue engineering. Curr Stem Cell Res Ther. 2013;8(5):400-6. [Medline: 23957935] [doi: 10.2174/1574888X113089990055]

53. Xiong J, Gronthos S, Bartold PM. Role of the epithelial cell rests of Malassez in the development, maintenance and regeneration of periodontal ligament tissues. Periodontol 2000. 2013;63(1):217-33. [Medline: 23931062] [doi: $10.1111 /$ prd.12023]

54. Fawzy el-sayed KM, Mekhemar MK, Beck-broichsitter BE, Bähr T, Hegab M, Receveur J, Heneweer C, Becker ST, Wiltfang J, Dörfer CE. Periodontal regeneration employing gingival margin-derived stem/progenitor cells in conjunction with IL-1ra-hydrogel synthetic extracellular matrix. J Clin Periodontol. 2015;42(5):448-57. [Medline: 25875208] [doi: 10.1111 jepe.12401]

55. Zhang H, Liu S, Zhu B, Xu Q, Ding Y, Jin Y. Composite cell sheet for periodontal regeneration: crosstalk between different types of MSCs in cell sheet facilitates complex periodontal-like tissue regeneration. Stem Cell Res Ther. 2016;7(1):168. [Medline: 27842561] [doi: 10.1186/s13287-016-0417-x]

56. Kim SH, Kim KH, Seo BM, Koo KT, Kim TI, Seol YJ, Ku Y, Rhyu IC, Chung CP, Lee YM. Alveolar bone regeneration by transplantation of periodontal ligament stem cells and bone marrow stem cells in a canine peri-implant defect model: a pilot study. J Periodontol. 2009;80(11):1815-23. [Medline: 19905951] [doi: 10.1902/jop.2009.090249]

57. Yan XZ, Van den beucken JJ, Cai X, Yu N, Jansen JA, Yang F. Periodontal tissue regeneration using enzymatically solidified chitosan hydrogels with or without cell loading. Tissue Eng Part A. 2015;21(5-6):1066-76. [Medline: 25345525] [doi: 10.1089/ten.tea.2014.0319]

58. Yu BH, Zhou Q, Wang ZL. Periodontal ligament versus bone marrow mesenchymal stem cells in combination with Bio-Oss scaffolds for ectopic and in situ bone formation: A comparative study in the rat. J Biomater Appl. 2014;29(2): 243-253. [Medline: 24487130] [doi: 10.1177/0885328214521846] 
59. Zhou Y, Li Y, Mao L, Peng H. Periodontal healing by periodontal ligament cell sheets in a teeth replantation model. Arch Oral Biol. 2012;57(2):169-76. [Medline: 21907971] [doi: 10.1016/j.archoralbio.2011.08.008]

60. Zheng Y, Liu Y, Zhang CM, Zhang HY, Li WH, Shi S, Le AD, Wang SL. Stem cells from deciduous tooth repair mandibular defect in swine. J Dent Res. 2009;88(3):249-54. [Medline: 19329459] [doi: 10.1177/0022034509333804]

61. Guo W, Chen L, Gong K, Ding B, Duan Y, Jin Y. Heterogeneous dental follicle cells and the regeneration of complex periodontal tissues. Tissue Eng Part A. 2012;18(5-6):459-70. [Medline: 21919800] [doi: 10.1089/ten.tea.2011.0261]

62. Jiang S, Tang K, Chen B, Yan F. Regenerative effect of hOPG gene-modified autologous PDLs in combination with cell transplantation on periodontal defection in beagle dogs. Cytotechnology. 2016 Dec;68(6):2613-2623. [Medline: 27221335] [PMC free article: 5101332] [doi: 10.1007/s10616-016-9985-y]

63. Nu-ez J, Sanz-Blasco S, Vignoletti F, Mu-oz F, Arzate H, Villalobos C, Nu-ez L, Caffesse RG, Sanz M. Periodontal regeneration following implantation of cementum and periodontal ligament-derived cells. J Periodont Res. 2012;47(1): 33-44. [Medline: 21906056] [doi: 10.1111/j.1600-0765.2011.01402.x]

64. Liu Y, Zheng Y, Ding G, Fang D, Zhang C, Bartold PM, Gronthos S, Shi S, Wang S. Periodontal ligament stem cellmediated treatment for periodontitis in miniature swine. Stem Cells. 2008;26(4):1065-73. 20. [Medline: 18238856] [doi: 10.1634/stemcells.2007-0734]

65. Jiang J, Wu X, Lin M, Doan N, Xiao Y, Yan F. Application of autologous periosteal cells for the regeneration of class III furcation defects in Beagle dogs. Cytotechnology. 2010 Jul;62(3):235-43. [Medline: 20582491] [doi: $10.1007 / \mathrm{s} 10616-010-9284-\mathrm{y}$ ]

66. Park JY, Jeon SH, Choung PH. Efficacy of periodontal stem cell transplantation in the treatment of advanced periodontitis. Cell Transplant. 2011;20(2):271-85. [Medline: 20719084] [doi: 10.3727/096368910X519292]

67. Suaid FF, Ribeiro FV, Rodrigues TL, Silvério KG, Carvalho MD, Nociti FH Jr, Casati MZ, Sallum EA. Autologous periodontal ligament cells in the treatment of class II furcation defects: a study in dogs. J Clin Periodontol. 2011;38(5): 491-8. [Medline: 21392047] [doi: 10.1111/j.1600-051X.2011.01715.x]

68. Tsumanuma Y, Iwata T, Washio K, Yoshida T, Yamada A, Takagi R, Ohno T, Lin K, Yamato M, Ishikawa I, Okano T, Izumi Y. Comparison of different tissue-derived stem cell sheets for periodontal regeneration in a canine 1-wall defect model. Biomaterials. 2011;32(25):5819-25. [Medline: 21605900] [doi: 10.1016/j.biomaterials.2011.04.071]

69. Suaid FF, Ribeiro FV, Rodrigues TL, Silvério KG, Carvalho MD, Nociti FH Jr, Casati MZ, Sallum EA. Autologous periodontal ligament cells in the treatment of Class III furcation defects: a study in dogs. J Clin Periodontol. 2012;39(4): 377-84. [Medline: 21392047] [doi: 10.1111/j.1600-051X.2011.01715.x]

70. Khorsand A, Eslaminejad MB, Arabsolghar M, Paknejad M, Ghaedi B, Rokn AR, Moslemi N, Nazarian H, Jahangir S. Autologous dental pulp stem cells in regeneration of defect created in canine periodontal tissue. J Oral Implantol. 2013;39(4):433-43. [Medline: 23964777] [doi: 10.1563/AAID-JOI-D-12-00027]

71. Tobita M, Uysal CA, Guo X, Hyakusoku H, Mizuno H. Periodontal tissue regeneration by combined implantation of adipose tissue-derived stem cells and platelet-rich plasma in a canine model. Cytotherapy. 2013;15(12):1517-26. [Medline: 23849975] [doi: 10.1016/j.jcyt.2013.05.007]

72. Chen FM, Wu LA, Zhang M, Zhang R, Sun HH. Homing of endogenous stem/progenitor cells for in situ tissue regeneration: Promises, strategies, and translational perspectives. Biomaterials. 2011;32(12):3189-209. [Medline: 21300401] [doi: 10.1016/j.biomaterials.2010.12.032]

73. Li Y, Zhao S, Nan X, Wei H, Shi J, Li A, Gou J. Repair of human periodontal bone defects by autologous grafting stem cells derived from inflammatory dental pulp tissues. Stem Cell Res Ther. 2016 Sep 22;7(1):141. [Medline: 27655627] [PMC free article: 5032237] [doi: 10.1186/s13287-016-0404-2]

74. Chen FM, Gao LN, Tian BM, Zhang XY, Zhang YJ, Dong GY, Lu H, Chu Q, Xu J, Yu Y, Wu RX, Yin Y, Shi S, Jin Y. Treatment of periodontal intrabony defects using autologous periodontal ligament stem cells: a randomized clinical trial. Stem Cell Res Ther. 2016 Feb 19;7:33. [Medline: 26895633] [PMC free article: 4761216] [doi: 10.1186/s13287-016-0288-1]

75. Zanwar K, Laxmanrao Bhongade M, Kumar Ganji K, B Koudale S, Gowda P. Comparative evaluation of efficacy of stem cells in combination with PLA/PGA membrane versus sub-epithelial connective tissue for the treatment of multiple gingival recession defects: a clinical study. J Stem Cells. 2014;9(4):253-67. [Medline: 25942341]

76. Kolind K, Leong KW, Besenbacher F, Foss M. Guidance of stem cell fate on 2D patterned surfaces. Biomaterials. 2012;33(28):6626-33. [Medline: 22748769] [doi: 10.1016/j.biomaterials.2012.05.070]

77. Saito A, Saito E, Handa R, Honma Y, Kawanami M. Influence of residual bone on recombinant human bone morphogenetic protein-2-induced periodontal regeneration in experimental periodontitis in dogs. J Periodontol. 2009;80(6):961-8. [Medline: 19485827] [doi: 10.1902/jop.2009.080568] 


\section{To cite this article:}

Gaubys A, Papeckys V, Pranskunas M.

Use of Autologous Stem Cells for the Regeneration of Periodontal Defects in Animal Studies: a Systematic Review and MetaAnalysis

J Oral Maxillofac Res 2018;9(2):e3

URL: http://www.ejomr.org/JOMR/archives/2018/2/e3/v9n2e3.pdf

doi: $10.5037 /$ jomr.2018.9203

Copyright (C) Gaubys A, Papeckys V, Pranskunas M. Published in the JOURNAL OF ORAL \& MAXILLOFACIAL RESEARCH (http://www.ejomr.org), 29 June 2018.

This is an open-access article, first published in the JOURNAL OF ORAL \& MAXILLOFACIAL RESEARCH, distributed under the terms of the Creative Commons Attribution-Noncommercial-No Derivative Works 3.0 Unported License, which permits unrestricted non-commercial use, distribution, and reproduction in any medium, provided the original work and is properly cited. The copyright, license information and link to the original publication on (http://www.ejomr.org) must be included. 